\title{
Molecularly tagged genes and quantitative trait loci in cucumber with recommendations for QTL nomenclature
}

\author{
Yuhui Wang ${ }^{1}$, Kailiang $\mathrm{Bo}^{2}$, Xingfang $\mathrm{Gu}^{2}$, Junsong Pan ${ }^{3}$, Yuhong $\mathrm{Li}^{4}$, Jinfeng Chen ${ }^{5}$, Changlong Wen', \\ Zhonghai Ren $\mathbb{1}^{7}$, Huazhong Ren ${ }^{8}$, Xuehao Chen ${ }^{9}$, Rebecca Grumet ${ }^{10}$ and Yiqun Weng $\mathbb{1}^{1,11}$
}

\begin{abstract}
Cucumber, Cucumis sativus L. $(2 n=2 x=14)$, is an important vegetable crop worldwide. It was the first specialty crop with a publicly available draft genome. Its relatively small, diploid genome, short life cycle, and selfcompatible mating system offers advantages for genetic studies. In recent years, significant progress has been made in molecular mapping, and identification of genes and QTL responsible for key phenotypic traits, but a systematic review of the work is lacking. Here, we conducted an extensive literature review on mutants, genes and QTL that have been molecularly mapped or characterized in cucumber. We documented 81 simply inherited trait genes or major-effect QTL that have been cloned or fine mapped. For each gene, detailed information was compiled including chromosome locations, allelic variants and associated polymorphisms, predicted functions, and diagnostic markers that could be used for marker-assisted selection in cucumber breeding. We also documented 322 QTL for 42 quantitative traits, including 109 for disease resistances against seven pathogens. By alignment of these QTL on the latest version of cucumber draft genomes, consensus QTL across multiple studies were inferred, which provided insights into heritable correlations among different traits. Through collaborative efforts among public and private cucumber researchers, we identified 130 quantitative traits and developed a set of recommendations for QTL nomenclature in cucumber. This is the first attempt to systematically summarize, analyze and inventory cucumber mutants, cloned or mapped genes and QTL, which should be a useful resource for the cucurbit research community.
\end{abstract}

\section{Introduction}

Cucumber, Cucumis sativus L., is among the most widely cultivated and consumed vegetable crops throughout the world. In 2017, cucumber was grown on 919,146 hectares with a total production of $83,753,861$ tons worldwide, and China is the largest producer with $77.4 \%$, and $54.4 \%$ total production and acreage of the world, respectively (www.fao.org/faostat/en/). Cucumber was the first among major horticulture crops with a

\footnotetext{
Correspondence: Yiqun Weng (yiqun.weng@ars.usda.gov)

'Department of Horticulture, University of Wisconsin, Madison, WI 53706, USA

${ }^{2}$ Institute of Vegetables and Flowers, Chinese Academy of Agricultural

Sciences, Beijing 100081, China

Full list of author information is available at the end of the article
}

publicly available draft genome. The small, diploid genome ( 400 Mbp), annual growth habit, self-compatible mating system, and relatively short life cycle ( $\sim 3$ months from seed to seed) offer significant advantages for genetic studies. The development of high-quality draft genomes and high-density genetic maps, coupled with utilization of high-throughput genotyping methods have greatly accelerated genetic mapping and gene/QTL cloning in cucumber. The 2016 Cucumber Gene Catalog documented 199 simply inherited genes or major-effect $\mathrm{QTL}^{1}$. In recent years, many genes listed in the catalog as well as new ones have been molecularly characterized or fine mapped. Hundreds of QTL for horticulturally important traits have been identified. While a wealth of 
data has been accumulated, a systematic review and inventory of the mutants, molecularly characterized or tagged genes, and QTL for cucumber is lacking. In addition, the QTL names used in various studies are inconsistent and confusing. It is imperative to develop a community standard for assignment of QTL names. Therefore, the objectives of this article are to: (1) review cloned and fine mapped genes or major-effect QTL. (2) Develop recommendations for QTL nomenclature for future QTL mapping studies. (3) Inventory published QTL in cucumber.

\section{Genes conferring simply inherited traits}

As of July 2019, candidate genes have been identified for 51 simply inherited traits in cucumber (Table 1). Genes for additional 30 traits have been fine mapped with the target loci delimited to $<2.0 \mathrm{Mbp}$ (Table 2). It should be pointed out that, we used "cloned gene" in this review not in its strict term because for many mutants, identification of the candidate genes was based on genetic evidence, and their functions have not been validated or verified. Also, some major-effect QTL were counted as simply inherited genes, which often contribute to $>20 \%$ observed phenotypic variance in QTL analysis. Details of the 81 genes are presented in supplementary File 1 (Table S1) including polymorphisms between the parents in the candidate gene, diagnostic markers, and primer sequences. Allelic variants for six genes ( $c u l, g l 1, g l 3, m, p m$, and $r l$ ) are listed separately in Table S1 (hence the total number is 88 ). The two variants of the CsGL3 gene exhibit different phenotypes, which are listed as two genes. Three genes have names that are duplicated with previously reported ones including glabrous $2(g l 2)^{2}$, ts (tender spine) $)^{3}$, and $s f-1$ $\left(\right.$ ref. $\left.^{4}\right)$, which were re-assigned $g l 4, t s p$, and $s f-2$, respectively. The CSSEP gene was the candidate for a mutant with very long sepals ${ }^{5}$, which was assigned els-1 (extralong sepal-1) in this work.

Among the 81 cloned or fine mapped genes or majoreffect QTL, 14 are EMS-induced mutations, and the rest are spontaneous mutations identified from natural populations. Of the 51 cloned candidate genes, 42 mutants are due to SNPs; other polymorphisms include small or large deletions, and retrotransposon insertions. In most cases, the SNPs or insertions result in frame shift or amino acid substitutions, or alternate splicing (supplementary File 1). For convenience, the 81 genes/QTL were classified into six categories: Vegetative organ (23), Flower (7), Fruit (28), Disease resistance (18), Abiotic stress tolerance (1), and Miscellaneous (MISC) (4). Phenotypes of some representative plant architecture, leaf or fruit mutants are shown in Fig. 1. Distribution of the 81 genes or QTL across 7 cucumber chromosomes are illustrated in Fig. 2.

\section{Establishment of controlled vocabularies to describe quantitative traits and recommendations for QTL nomenclature in cucumber}

Most horticulturally important traits in cucumber are controlled by QTL. With the exponential increase of QTL mapping studies in cucumber, one complicating issue is the naming of quantitative traits and corresponding QTL, which is currently very confusing. It is common that the same name was used for different traits or different names were used for the same trait. Thus, we reviewed the literature and phenotyping manuals from both public institutions and private seed companies. We also consulted colleagues in the cucumber research community and proposed the following rules for use of abbreviations to name quantitative traits in cucumber.

1. For disease/insect resistances: use common names except for Fusarium wilt and Fusarium crown rot, for which FOC and FCROS have been widely used, respectively.

2. For a trait name with one word, use first three letters.

3. For a trait name with two words, use the initial from each word. In a few cases, three letters (one from the initial of one word and two from another word) are used to avoid duplication with other traits, or for better understanding of its meaning.

4. For traits with more than two words, use the initial from each word.

Based on inputs from the community, 130 quantitative traits were identified. Their full names and recommended QTL names (abbreviations) are listed in Table 3. Considering the common practices taken by the cucurbit research community, we also recommend the following rules in assigning QTL names:

1. QTL name format: Trait name.chr\#.QTL order on chromosome.

2. When multiple QTL on the same chromosome (linkage group) are reported for the same trait, the numbering order follows the order of discovery in the literature.

3. The use of capital or lower case letters depends on the inheritance of the trait (dominant, co-dominant, or recessive).

Thus, par6.2 is the second QTL of parthenocarpic fruit set on Chr6 (more parthenocarpic fruit is recessive); Pm1.1 is the first QTL of powdery mildew resistance on Chr1 (resistance is dominant); FS5.3 is the third consensus fruit size QTL on Chr5, and $f$ sd6.2 is the second QTL for fruit spine density on Chr6. These rules will be applied in the following discussions for all QTL described but original names are also included for clarity.

For convenience, the 130 quantitative traits were classified into eight categories: Vegetative organ (22), Flower 


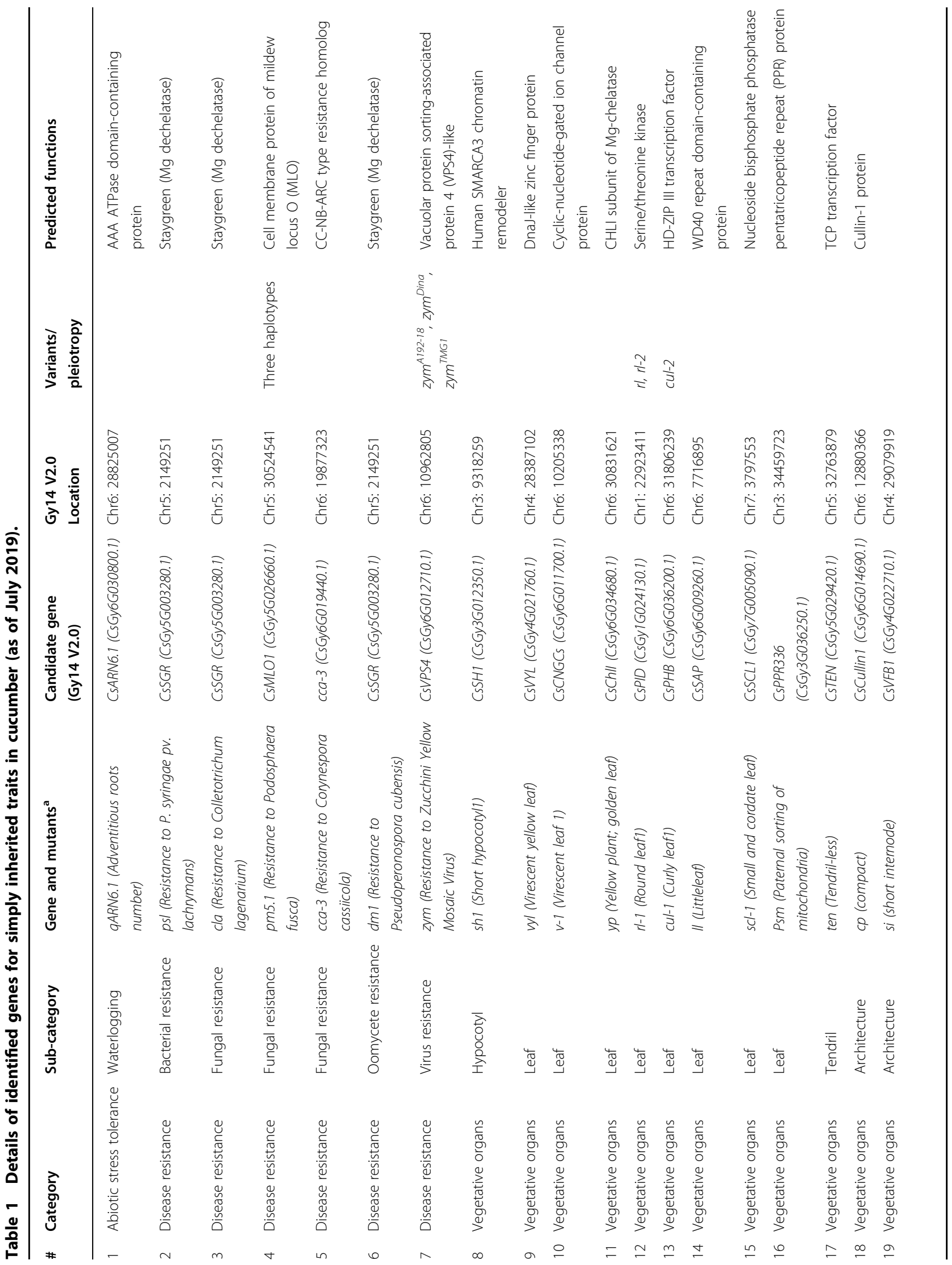






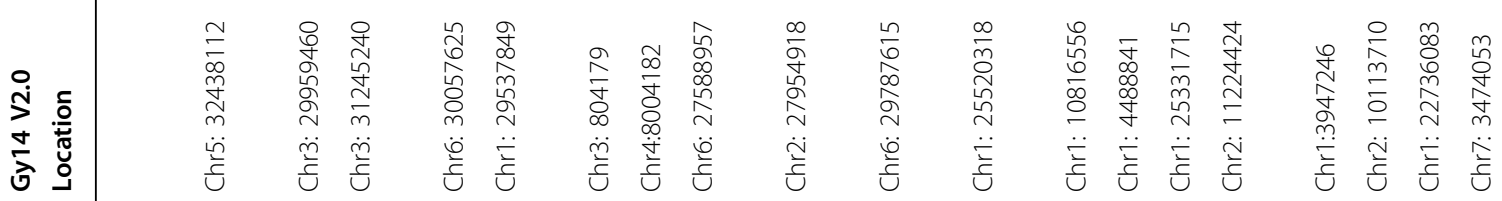
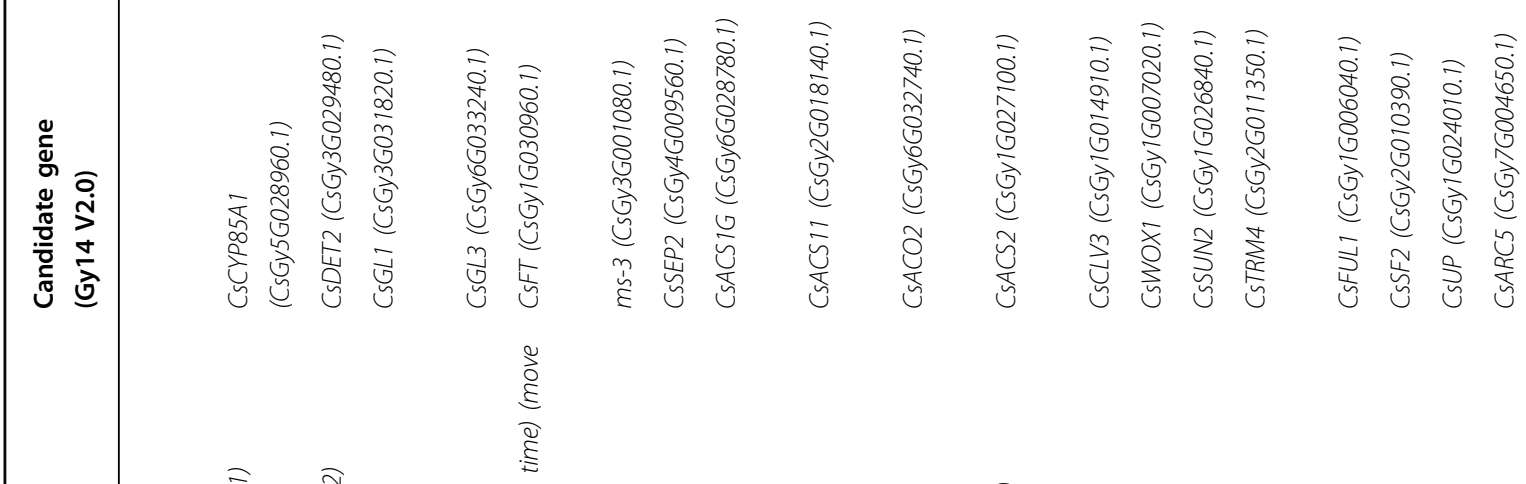

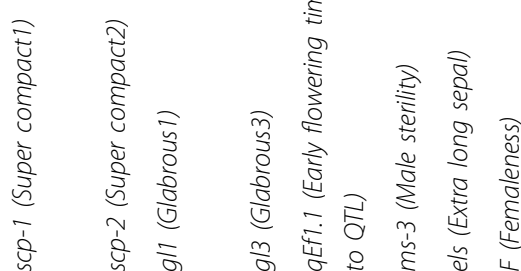

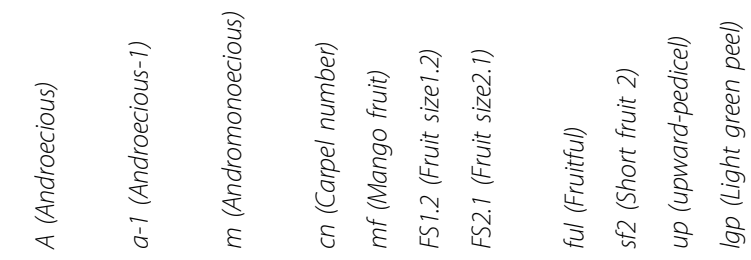

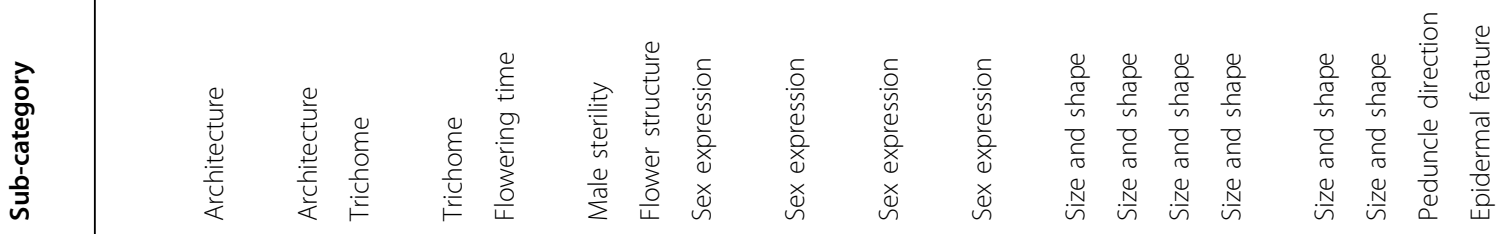

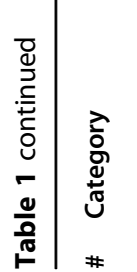

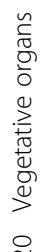

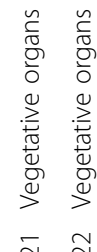



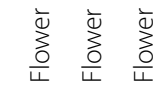

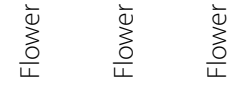

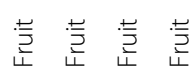

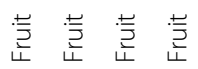

$\sim \stackrel{\infty}{\sim} \stackrel{\infty}{\sim}$

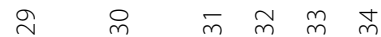

$\stackrel{n}{m} \stackrel{\infty}{m} \stackrel{\infty}{m}$ 


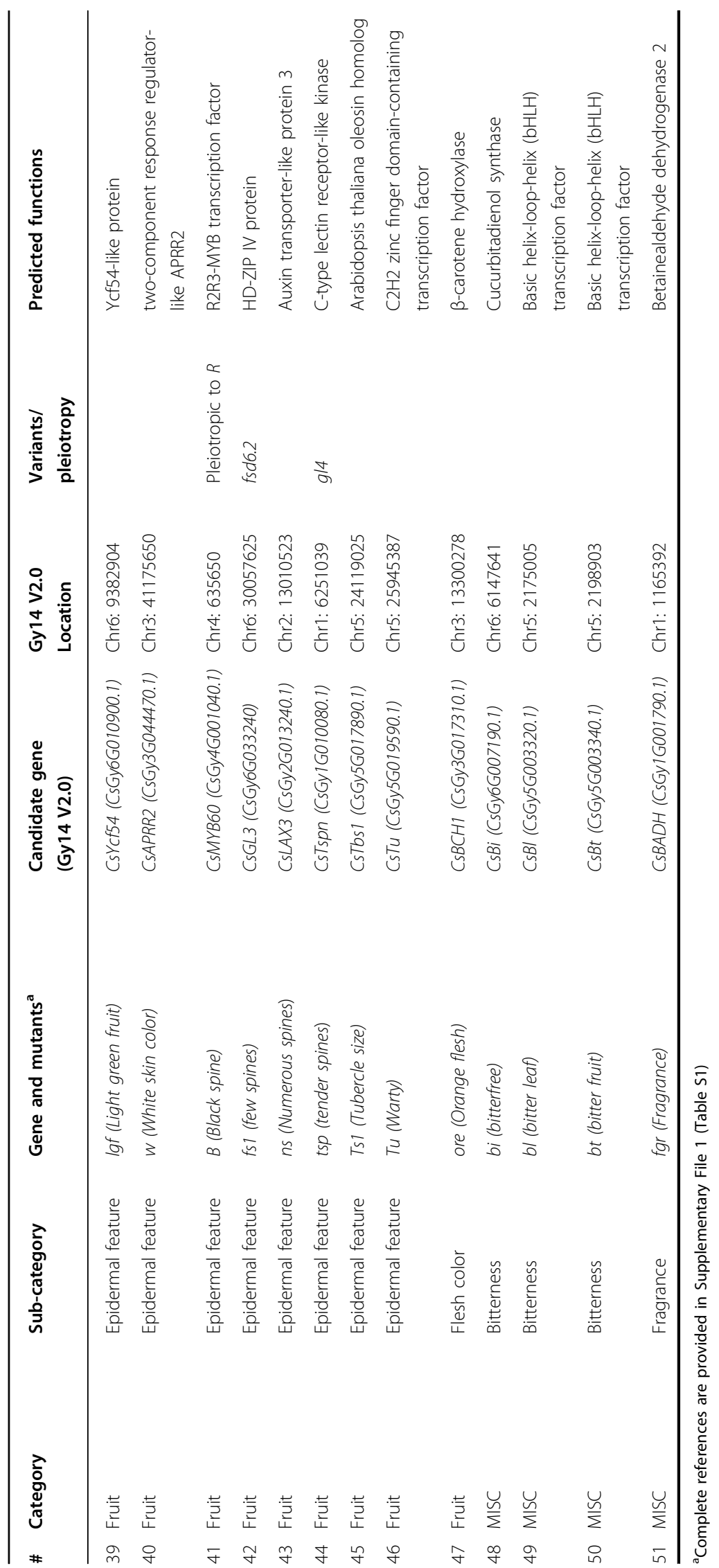


Table 2 List of fine mapped genes or major-effect QTL in cucumber (as of July 2019).

\begin{tabular}{|c|c|c|c|c|c|}
\hline$\#$ & Category & Sub-category & Gene and mutants ${ }^{\mathrm{a}}$ & Gy14 V2.0 Location & Physical Interval ${ }^{\mathbf{b}}$ \\
\hline 1 & Vegetative organ & Leaf & vl (variegated leaf) & Chr6:21297426 & $\mathrm{n} / \mathrm{a}$ \\
\hline 2 & Vegetative organ & Leaf & II-2 (littleleaf -2) & Chr7:1705258 & $1.24 \mathrm{Mb}$ \\
\hline 3 & Vegetative organ & Tendril & $t d-1$ (tendrilles-1) & Chr6:32202841 & $190 \mathrm{~kb}$ \\
\hline 4 & Vegetative organ & Trichome & gl2 (Glabrous2) & Chr2:20772692 & $0.6 \mathrm{cM}$ \\
\hline 5 & Vegetative organ & Trichome & g/4 (g/2, glabrous2) & Chr1:6247822 & $720 \mathrm{~kb}$ \\
\hline 6 & Vegetative organ & Architecture & $c p-1$ (compact1) & Chr4:29878253 & $178 \mathrm{~kb}$ \\
\hline 7 & Vegetative organ & Architecture & $d w(d w a r f)$ & Chr3:38398789 & $\mathrm{n} / \mathrm{a}$ \\
\hline 8 & Fruit & Epidermal feature & ygp (Yellow green peel) & Chr2: 27932225 & $\mathrm{n} / \mathrm{a}$ \\
\hline 9 & Fruit & Epidermal feature & u (uniform immature fruit color) & Chr5:25663570 & $313.2 \mathrm{~kb}$ \\
\hline 10 & Fruit & Epidermal feature & D (Dull fruit skin) & Chr5:26438292 & $244.9 \mathrm{~kb}$ \\
\hline 11 & Fruit & Epidermal feature & H (Heavy netting) & Chr5:25709527 & $1.2 \mathrm{Mb}$ \\
\hline 12 & Fruit & Epidermal feature & Pe (Palisade epidermis) & Chr5:25915175 & $227.5 \mathrm{~kb}$ \\
\hline 13 & Fruit & Epidermal feature & Fr (Fruit ribbing) & Chr5:26431293 & $2.4 \mathrm{cM}$ \\
\hline 14 & Fruit & Epidermal feature & Te (Tender fruit skin) & Chr5:26000000 & $n / a$ \\
\hline 15 & Fruit & Epidermal feature & ss (small spine) & Chr5:25972294 & $189 \mathrm{~kb}$ \\
\hline 16 & Fruit & Flesh & yf (yellow flesh) & Chr7:19537576 & $149 \mathrm{~kb}$ \\
\hline 17 & Fruit & Flesh & fth2.1 (Fruit flesh thickness2.1) & Chr2: 4434893 & $190 \mathrm{~kb}$ \\
\hline 18 & Fruit & Size and shape & sf-1 (short fruit-1) & Chr6:11696118 & $174.3 \mathrm{~kb}$ \\
\hline 19 & Disease resistance & Fungal resistance & Foc (Resistance F. oxysporum f. sp. Cucumerinum) & Chr2:3276171 & $740 \mathrm{~kb}$ \\
\hline 20 & Disease resistance & Fungal resistance & pm1.1 (Resistance Podosphaera fusca) & Chr1:6841559 & $41.1 \mathrm{~kb}$ \\
\hline 21 & Disease resistance & Fungal resistance & pm-s (Resistance Podosphaera fusca) & Chr5:30406396 & $135.7 \mathrm{~kb}$ \\
\hline 22 & Disease resistance & Fungal resistance & pm5.3 (Resistance Podosphaera fusca) & Chr5:30434472 & $468.0 \mathrm{~kb}$ \\
\hline 23 & Disease resistance & Fungal resistance & cca-1 (Resistance to Corynespora cassiicola) & Chr6:17894751 & $2.9 \mathrm{cM}$ \\
\hline 24 & Disease resistance & Fungal resistance & cca-2 (Resistance to Corynespora cassiicola) & Chr6:9468049 & $1.25 \mathrm{Mb}$ \\
\hline 25 & Disease resistance & Fungal resistance & ccu (Resistance to Cladosporium cucumerinum) & Chr2:3276171 & $180 \mathrm{~kb}$ \\
\hline 26 & Disease resistance & Oomycete resistance & dm4.1 (Pseudoperonospora cubensise) & Chr4:22679946 & $322 \mathrm{~kb}$ \\
\hline 27 & Disease resistance & Oomycete resistance & dm5.2 (Pseudoperonospora cubensis) & Chr5:23380844 & $628 \mathrm{~kb}$ \\
\hline 28 & Disease resistance & Virus resistance & cmv6.1 (Resistance to cucumber mosaic virus) & Chr6:7688887 & $1.62 \mathrm{Mb}$ \\
\hline 29 & Disease resistance & Virus resistance & PRSV (Resistance to Papaya ringspot virus) & Chr6:9726336 & $1.8 \mathrm{cM}$ \\
\hline 30 & Disease resistance & Virus resistance & wmv (Resistance to watermelon mosaic virus) & Chr6:22530869 & $134.7 \mathrm{~kb}$ \\
\hline
\end{tabular}

${ }^{a}$ Complete reference is provided in Supplementary File 1 (Table S1)

${ }^{b}$ Estimated by flanking markers; $\mathrm{n} / \mathrm{a}=$ not available or not applicable

${ }^{\mathrm{c}}$ Estimated from the Tender fruit $(T e)$ location

(9), Fruit (50), Seed (6), Abiotic stress tolerance (7), Disease resistance (26), Insect resistance (9), and Miscellaneous (MISC) (1). Under each category, there are also subcategories based on specific plant organs, pathogens, or abiotic stresses (Table 3). In the following sections, under each category, we will briefly discuss selected simply inherited genes and QTL for phenotypic characteristics and their potential in cucumber breeding. Many genes and QTL have a long history of research, but only the most recent literature was cited in the text to save space. The complete list of genes/QTL and references is provided in three supplemental files (1, 2 and 3). For many genes and majoreffect QTL, readers can also consult the 2016 Cucumber Gene Catalog ${ }^{1}$ for complete historical references. 


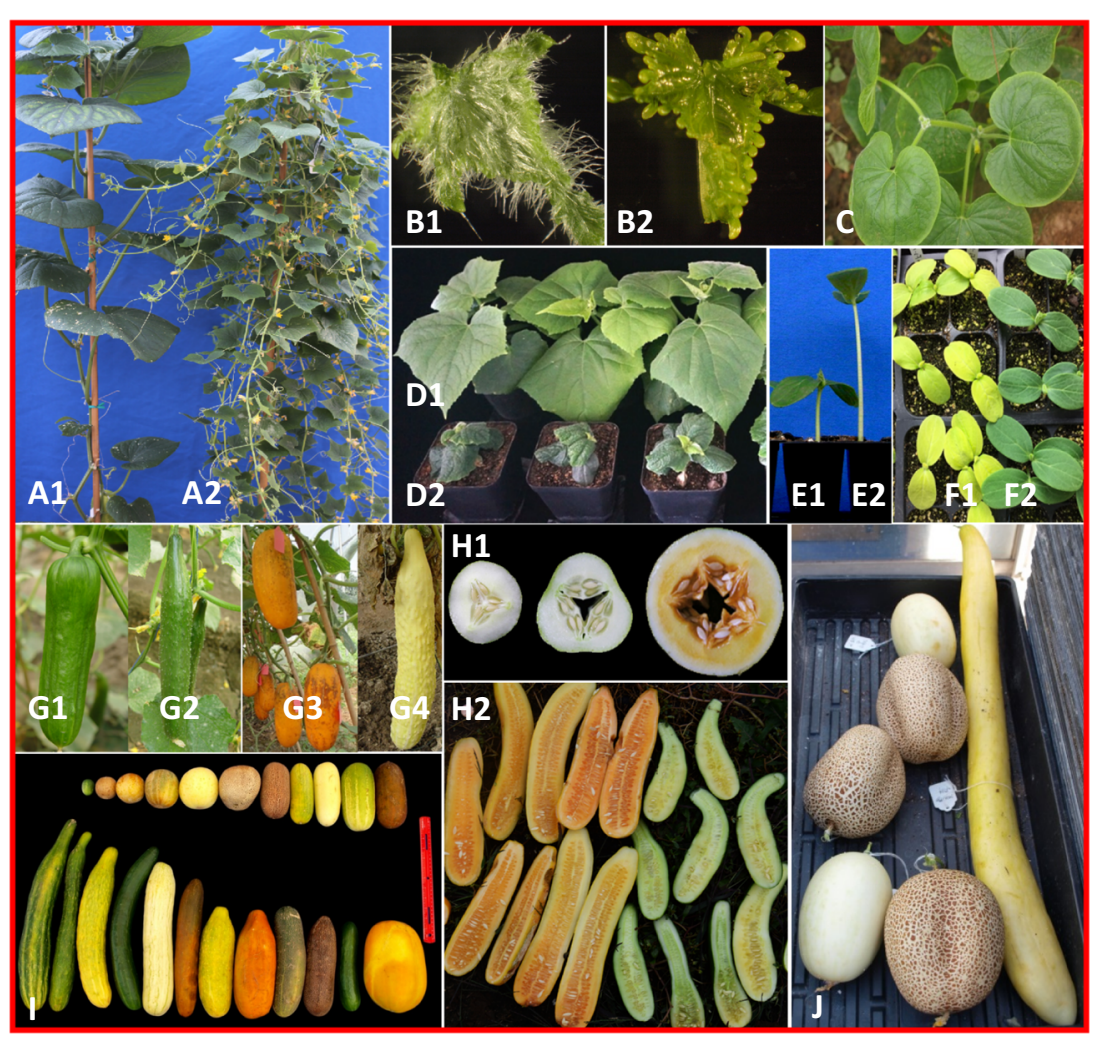

Fig. 1 Phenotypes of representative mutants in cucumber. a-f shows mutant and wild-type phenotypes for littleleaf (II, A2), glabrous3 (g/3, B2), roundleaf $(r l, \mathbf{c})$, super compact-1 (scp-1, D2), short hypocotyl1 (sh1, E1), yellow plant (yp, F1), respectively. $\mathbf{g}$ thru $\mathbf{j}$ show phenotypic variation in spine size and density (g), fruit flesh color (white, orange, yellow, and green), cavity size (h), fruit size, shape, and fruit epidermal features (i, $\mathbf{j})$ in natural populations.
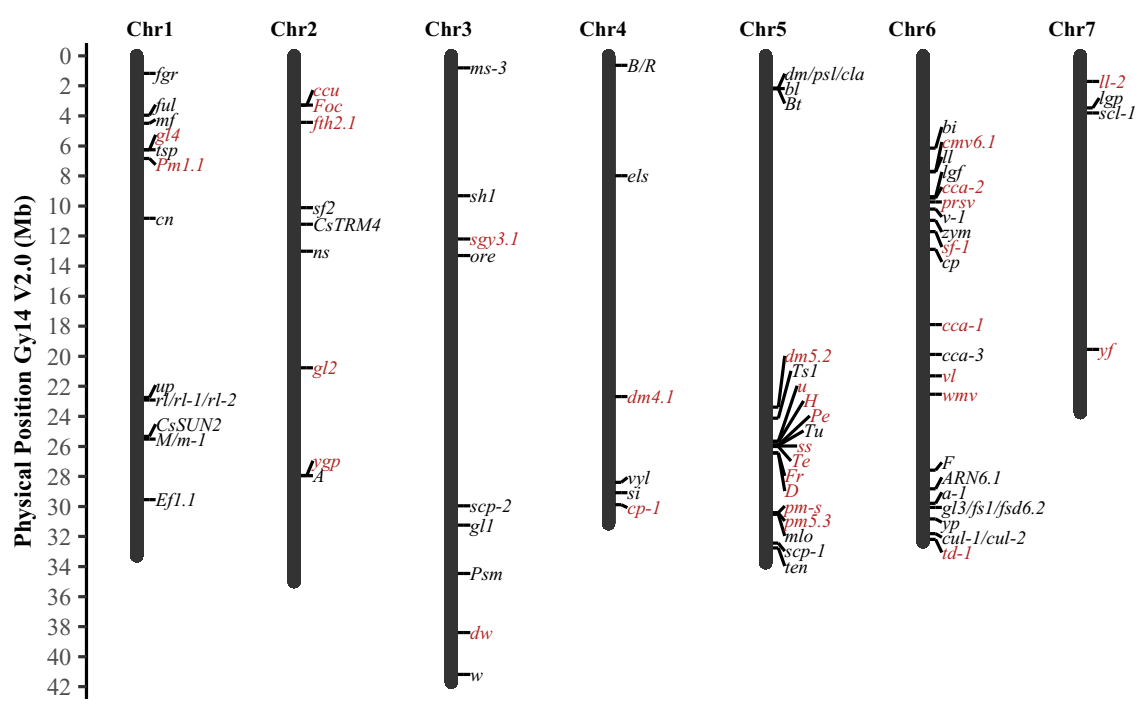

Fig. 2 Chromosomal locations of $\mathbf{8 1}$ cloned (black) or fine mapped (red) genes in cucumber. Ruler to the left indicates locations (in Mbp) in the Gy14 V2.0 draft genome assembly (drawn to scale). 
Table 3 Proposed nomenclature for quantitative traits in QTL mapping studies in cucumber.

\begin{tabular}{|c|c|c|c|c|}
\hline$\#$ & Category & Sub-category & Traits & Abbreviations \\
\hline 1 & Abiotic stress tolerance & Chilling tolerance & Chilling Tolerance & $C T$ \\
\hline 2 & Abiotic stress tolerance & Low temperature germination & Low Temperature Germination & LTG \\
\hline 3 & Abiotic stress tolerance & Drought tolerance & Water Deficit Tolerance & WDT \\
\hline 4 & Abiotic stress tolerance & Heat tolerance & Heat Tolerance & HT \\
\hline 5 & Abiotic stress tolerance & Waterlogging tolerance & Adventitious Root Number & ARN \\
\hline 6 & Abiotic stress tolerance & Waterlogging tolerance & Waterlogging Tolerance & WLT \\
\hline 7 & Abiotic stress tolerance & Sulfur tolerance & Sulfur Tolerance & ST \\
\hline 8 & Disease resistance & Disease development & Chlorosis & $\mathrm{CHL}$ \\
\hline 9 & Disease resistance & Disease development & Necrosis & NEC \\
\hline 10 & Disease resistance & Disease development & Sporulation & SPR \\
\hline 11 & Disease resistance & Bacterial resistance & Resistance to Angular Leaf Spot (P. syringae pv. Lachryman) & ALS \\
\hline 12 & Disease resistance & Bacterial resistance & Resistance to Bacterial Wilt (Erwinia tracheiphila) & BW \\
\hline 13 & Disease resistance & Fungal resistance & Resistance to Anthracnose (Colletotrichum lagenarium) & AN \\
\hline 14 & Disease resistance & Fungal resistance & Resistance to Scab (Cladosporium cucumerinum) & SC \\
\hline 15 & Disease resistance & Fungal resistance & Resistance to Fusarium oxysporum f. sp. cucumerinum (Fusarium Wilt) & FOC \\
\hline 16 & Disease resistance & Fungal resistance & Resistance to F. oxysporum f. sp. radicis-cucumerinum(Fusarium crown rot) & FCRO \\
\hline 17 & Disease resistance & Fungal resistance & Resistance to Gray Mold (Botrytis cinerea) & GM \\
\hline 18 & Disease resistance & Fungal resistance & Resistance to Gummy Stem Blight (Didymella bryoniae) & GSB \\
\hline 19 & Disease resistance & Fungal resistance & Resistance to Phytophthora Fruit Rot (Phytophthora capsici) & PFR \\
\hline 20 & Disease resistance & Fungal resistance & Resistance to Powdery Mildew (Podosphaera fusca) & PM \\
\hline 21 & Disease resistance & Fungal resistance & Resistance to Target Leaf Spot (Corynespora cassiicola) & TLS \\
\hline 22 & Disease resistance & Nematode resistance & Resistance to Java Rootknot Nematode (Meloidogyne javanica) & JRN \\
\hline 23 & Disease resistance & Nematode resistance & Resistance to Southern Rootknot Nematode (Meloidogyne incognita) & SRN \\
\hline 24 & Disease resistance & Oomycete resistance & Resistance to Downy Mildew (Pseudoperonospora cubensis) & DM \\
\hline 25 & Disease resistance & Virus resistance & Resistance to Cucumber Green Mottle Mosaic Virus & CGMMV \\
\hline 26 & Disease resistance & Virus resistance & Resistance to Cucumber Mosaic Virus & CMV \\
\hline 27 & Disease resistance & Virus resistance & Resistance to Cucumber Vein Yellowing Virus & CVYV \\
\hline 28 & Disease resistance & Virus resistance & Resistance to Cucurbit Yellow Stunting Disorder Virus & CYSDV \\
\hline 29 & Disease resistance & Virus resistance & Resistance to Melon Yellow Spot Virus & MYSV \\
\hline 30 & Disease resistance & Virus resistance & Resistance to Papaya Ringspot Virus & PRSV \\
\hline 31 & Disease resistance & Virus resistance & Resistance to Tomato Leaf Curl New Delhi Virus & ToLCNDV \\
\hline 32 & Disease resistance & Virus resistance & Resistance to Watermelon Mosaic Virus & WMV \\
\hline 33 & Disease resistance & Virus resistance & Resistance to Zucchini Yellow Mosaic Virus & ZYMV \\
\hline 34 & Insect resistance & Aphid & Resistance to melon/cotton aphid (Aphis gossypii) & MA \\
\hline 35 & Insect resistance & Cucumber beetle & Resistance to Banded Cucumber Beetle (Diabrotica balteata) & $\mathrm{BCB}$ \\
\hline 36 & Insect resistance & Cucumber beetle & Resistance to Spotted Cucumber Beetle (Diabrotica undecimpunctata) & SCB \\
\hline 37 & Insect resistance & Cucumber beetle & Resistance to Striped Cucumber Beetle (Acalymma vittatum) & STB \\
\hline 38 & Insect resistance & Leaf folder & Resistance to Leaf Folder (Diaphania indica) & LF \\
\hline 39 & Insect resistance & Leaf miner & Resistance to Leaf Miner (Liriomyza huidobrensis) & LM \\
\hline 40 & Insect resistance & Pickleworm & Resistance to Pickleworm (Diaphania nitidalis) & PKW \\
\hline 41 & Insect resistance & Thrips & Resistance to Thrips (Thrips palmi) & THR \\
\hline 42 & Insect resistance & Whiteflies & Resistance to Whiteflies (Bemisia tabaci) & WFL \\
\hline 43 & Vegetative organ & Hypocotyl & Hypocotyl Length & $\mathrm{HL}$ \\
\hline 44 & Vegetative organ & Cotyledon & Cotyledon Area (size) & CA \\
\hline 45 & Vegetative organ & Cotyledon & Cotyledon Length & $\mathrm{CL}$ \\
\hline 46 & Vegetative organ & Cotyledon & Cotyledon Width & CW \\
\hline 47 & Vegetative organ & Leaf & Leaf Bitterness & LB \\
\hline 48 & Vegetative organ & Leaf & Leaf Apex-Terminal-Lobe Angle & LAA \\
\hline 49 & Vegetative organ & Leaf & Leaf Area (size) & LA \\
\hline 50 & Vegetative organ & Leaf & Leaf Attitude & LAT \\
\hline 51 & Vegetative organ & Leaf & Leaf Blade Length (base to apex) & LBL \\
\hline 52 & Vegetative organ & Leaf & Leaf Blade Width & LBW \\
\hline 53 & Vegetative organ & Leaf & Leaf Margin Dentation & LMD \\
\hline 54 & Vegetative organ & Leaf & Leaf Margin Undulation & LMU \\
\hline
\end{tabular}


Table 3 continued

\begin{tabular}{|c|c|c|c|c|}
\hline$\#$ & Category & Sub-category & Traits & Abbreviations \\
\hline 55 & Vegetative organ & Leaf & Leaf Petiole Length & LPL \\
\hline 56 & Vegetative organ & Leaf & Trichomes (Vestiture) & $\mathrm{TRI}$ \\
\hline 57 & Vegetative organ & Vine & Internode Length & IL \\
\hline 58 & Vegetative organ & Vine & Node Number (total) & NN \\
\hline 59 & Vegetative organ & Vine & Vine Length (plant height) & $\mathrm{VL}$ \\
\hline 60 & Vegetative organ & Branch & Lateral Branches Number (primary) & LBN \\
\hline 61 & Vegetative organ & Root & Root Length (primary) & $\mathrm{RL}$ \\
\hline 62 & Vegetative organ & Root & Root Number (primary) & RN \\
\hline 63 & Vegetative organ & Root & Root Weight (biomass) & RW \\
\hline 64 & Vegetative organ & Plant & Biomass (whole plant dry weight) & $\mathrm{BIO}$ \\
\hline 65 & Flower & Flowering time & (First) Female Flowering Time & FFT \\
\hline 66 & Flower & Flowering time & First Flower Node (Position) & FFN \\
\hline 67 & Flower & Flowering time & (First) Male Flowering Time & MFT \\
\hline 68 & Flower & Flowering time & Flowering Time (days to anthesis) & FT \\
\hline 69 & Flower & Sex expression & Female Flower Positions (on main stem and branches) & FFP \\
\hline 70 & Flower & Sex expression & Multiple Pistillate Flowers (per node) & MPF \\
\hline 71 & Flower & Sex expression & Percentage of Female Flowers (on main stem) & PFF \\
\hline 72 & Flower & Sex expression & Percentage of Male Flowers (on main stem) & PMF \\
\hline 73 & Flower & Sex expression & Sub-gynoecious & SGY \\
\hline 74 & Fruit & Fruit setting & Parthenocarpy (fruit set) & PAR \\
\hline 75 & Fruit & Fruit setting & Fruit Setting Positions (\# fruits on main stem and branches) & FSP \\
\hline 76 & Fruit & Fruit number & Fruit Number (per plant at harvest) & FN \\
\hline 77 & Fruit & Fruit growth rate & Fruit Growth Rate & FGR \\
\hline 78 & Fruit & Epidermal feature & Fruit Creasing & FCR \\
\hline 79 & Fruit & Epidermal feature & Fruit Ribbing & FRB \\
\hline 80 & Fruit & Epidermal feature & Fruit Striping (number and length) & FST \\
\hline 81 & Fruit & Epidermal feature & Fruit Skin Netting (reticulation) & FSN \\
\hline 82 & Fruit & Epidermal feature & Fruit Skin Wax (Glaucosity) & FSW \\
\hline 83 & Fruit & Epidermal feature & Fruit Skin Glossiness & FSG \\
\hline 84 & Fruit & Epidermal feature & Fruit Skin Mottling & FSM \\
\hline 85 & Fruit & Epidermal feature & Fruit Ground Color (commercial fruit stage) & FGC \\
\hline 86 & Fruit & Epidermal feature & Fruit Ground Color-Mature & FGCM \\
\hline 87 & Fruit & Epidermal feature & Fruit Spine Color & FSC \\
\hline 88 & Fruit & Epidermal feature & Fruit Spine Density & FSD \\
\hline 89 & Fruit & Epidermal feature & Fruit Spine Size & FSS \\
\hline 90 & Fruit & Epidermal feature & Fruit Wart Density & FWD \\
\hline 91 & Fruit & Epidermal feature & Fruit Wart Size & FWS \\
\hline 92 & Fruit & Shape/Size & Ovary Diameter & OD \\
\hline 93 & Fruit & Shape/Size & Ovary Length & $\mathrm{OL}$ \\
\hline 94 & Fruit & Shape/Size & Ovary Shape Index & OSI \\
\hline 95 & Fruit & Shape/Size & Fruit Diameter (Commercial Stage) & FD \\
\hline 96 & Fruit & Shape/Size & Fruit Length (Commercial Stage) & $\mathrm{FL}$ \\
\hline 97 & Fruit & Shape/Size & Fruit Shape Index (Commercial Stage) & $\mathrm{FSI}$ \\
\hline 98 & Fruit & Shape/Size & Mature Fruit Diameter & MFD \\
\hline 99 & Fruit & Shape/Size & Mature Fruit Length & MFL \\
\hline 100 & Fruit & Shape/Size & Mature Fruit Shape Index & MFSI \\
\hline 101 & Fruit & Shape/Size & Fruit Size (consensus QTL) & FS \\
\hline 102 & Fruit & Shape/Size & Fruit Stem End & FSE \\
\hline 103 & Fruit & Shape/Size & Fruit Blossom End & FBE \\
\hline 104 & Fruit & Shape/Size & Fruit Neck Length & $\mathrm{FNL}$ \\
\hline 105 & Fruit & Shape/Size & Fruit Hollowness & $\mathrm{FH}$ \\
\hline 106 & Fruit & Shape/Size & Fruit Weight & FW \\
\hline 107 & Fruit & Biomass & Fruit Dry Matter & FDM \\
\hline 108 & Fruit & Peduncle & Fruit Peduncle Direction & FPD \\
\hline
\end{tabular}


Table 3 continued

\begin{tabular}{lllll}
\hline$\#$ & Category & Sub-category & Traits & Abbreviations \\
\hline 109 & Fruit & Peduncle & Fruit Peduncle Length & FPL \\
110 & Fruit & Flesh & Flesh Bitterness & FBI \\
111 & Fruit & Flesh & Flesh Color & FLC \\
112 & Fruit & Flesh & Fruit Firmness & FFI \\
113 & Fruit & Flesh & Fruit Flesh Thickness & FTH \\
114 & Fruit & Flesh & Seed Cavity Size & SCS \\
115 & Fruit & Taste quality & Acerbity & ACE \\
116 & Fruit & Taste quality & Fructity & ACl \\
117 & Fruit & Taste quality & Fruit Water Content & FRU \\
118 & Fruit & Taste quality & Glucose & FWC \\
119 & Fruit & Taste quality & Sucrose & GLU \\
120 & Fruit & Taste quality & Total Soluble Solids & SUC \\
121 & Fruit & Taste quality & Fruit Abscission & TSS \\
122 & Fruit & Maturity & Fruit Shelf Life & FAB \\
123 & Fruit & Shelf life & Seed Dormancy & FSL \\
124 & Seed & Seed dormancy & Seed Number (per fruit) & SD \\
125 & Seed & Seed number & Seed Length & SN \\
126 & Seed & Seed size & Seed Size & SDL \\
127 & Seed & Seed size & Seed Width & SDS \\
128 & Seed & Seed size & 100-Seed Weight & SW \\
129 & Seed & Seed weight & Regeneration ability (on MS medium) & 100SW \\
130 & MISC & MISC & & RA \\
\hline
\end{tabular}

\section{Genes and QTL for whole plant vegetative growth and development}

Simply inherited genes for mutants of vegetative organs

Due to the ease of identification, mutants for foliage characteristics and plant architecture traits such as leaf shape, size, color, and plant height or vine length are frequently reported. Genes responsible for eight cucumber leaf mutants have been identified. The five leaf color mutants are $y p$ (yellow plant $)^{6}, v-1$ (virescent leaf- 1$)^{7}, v l$

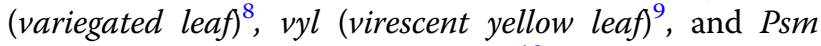
(Paternal sorting of mitochondria $)^{10}$. These mutations show a range of phenotypes. The $y p$ plant exhibits golden yellow color throughput its life. In the $v-1$ mutant, the cotyledons and first 2-3 true leaves are light yellow that turn to green when fully expanded; subsequent true leaves are green from the beginning. The young leaves on the $v y l$ mutant are yellow and gradually turn green when mature, whereas all leaves of the $v l$ mutant show a green and light yellow/white variegation which is especially obvious on younger leaves. All these mutants show some degree of retarded growth and reduced vine length, but the fertility and fruit set seem unaffected. The $Y p$ gene $(C s C H L I)$ is a homolog of the gene for the $\mathrm{Mg}$ chelatase I subunit; $\mathrm{Mg}$ chelatase is a rate-limiting enzyme in the chlorophyll biosynthesis pathway. The candidate gene for $V y l$ is predicted to encode a DnaJ-like zinc finger protein involved in regulation of chloroplast development, whereas $v-1$ seems to encode a cyclic-nucleotide-gated ion channel protein (CsCGNC). The nuclear pentatricopeptide repeat 336 gene (CsPPR336) is the candidate for the Psm locus underlying paternally transmitted mosaic phenotypes ${ }^{10}$.

Wild type cucumber leaves are flat and have seven lobes with toothed or smooth margin. Three non-lobe, round leaf mutants, $r l-1, r l-2$ and $r l$ have been identified, which are all due to allelic mutations in the PINOID (CSPID) gene encoding a regulator for the auxin polar transporter PIN (PIN-FORMED) ${ }^{11,12}$.

The leaf margin of the two curly leaf mutants, cul-1 and cul-2 rolls upward forming a shallow cup; both mutants are due to allelic mutations in the CsPHB gene for a class III homeodomain-leucine zipper (HD-ZIP III) transcription factor $^{13}$. The tendrilless (ten) mutation is caused by a SNP in the TEN gene encoding a TCP transcription factor ${ }^{14}$. Another tendrilless-1 $(t d-1)$ mutation has been mapped to a $\sim 190 \mathrm{~kb}$ region in Chr6 (ref. ${ }^{15}$ ). The phenotypes of the two tendrilless mutants are very different; ten is phenotypically normal except that the 'tendril' develops into leaves with long petioles and thin branches, whereas $t d-1$ mutation has more widespread pleiotropic effects.

The littleleaf $(l l)$ mutant, which produces leaves approximately one quarter of the size of standard American pickling cucumbers, was identified $\sim 40$ years ago. $L L$ is a homolog of Arabidopsis STERILE APETALA (CSSAP) encoding a WD40 repeat domain-containing protein ${ }^{16}$. QTL analysis revealed co-localization of major-effect QTL for fruit size, fruit weight, seed weight, and multiple lateral 
branches with the $L L$ locus indicating pleiotropic effects of the $l l$ mutation. In addition, $l l$ cucumbers often have poor internal fruit quality, which may hinder its use in pickling cucumber breeding.

Plant architecture, especially plant height or vine length, is important in cucumber breeding. So far, six mutants with reduced internode length or compact growth habit have been reported including compact $(c p)^{17}$, compact-1 $(c p-1)^{18}$, short internode $(s i)^{19}$, super compact-1 $(s c p-1)^{20}$, super compact-2 $(s c p-2)^{21}$, and dwarf $(d w)^{22}$. The $c p-1$, $d w, s c p-1$, and $s c p-2$ mutants have extremely short internodes with little value in practical use. Both $s c p-1$ and $s c p$ 2 are due to mutations of genes in the brassinosteroid (BR) biosynthesis pathway including CsCYP85A for the BR-C6-oxidase, and CsDET2 for the steroid 5-alphareductase $^{20,21}$. The si mutant exhibits short internode ( $50 \%$ of WT) and small fruit, which is a homolog for the gene encoding a member of the VIER F-BOX PROTEIN subfamily of the F-Box protein family $(C s V F B 1)^{19}$.

Hypocotyl elongation of modern commercial cucumbers is sensitive to environmental conditions. For example, high temperature or low light intensity may increase hypocotyl length resulting in poor seedling quality for transplanting. The semi-wild Xishuangbanna (C.s. var. xishuangbannesis, XIS) and wild (C.s. var. hardwickii, HARD) cucumber populations are enriched with the short hypocotl1 (sh1) allele, which renders hypocotyl elongation insensitive to UVB-free light and temperature changes ${ }^{23}$. Sh1 (CsSH1) is a homolog of the gene encoding a human SMARCA3-like chromatin remodeling factor. The sh1 mutation may be of value in use for mass seedling production in protected environments.

Four glabrous (trichome-free) mutants have been reported. The "glabrous1" (csgl1) or "microtrichome" (mict) mutant shows no visible trichomes on all aerial organs except the hypocotyl. CsGL1 encodes a Class I HD-ZIP transcription factor ${ }^{24,25}$. The $c s g l 2$ mutant exhibits glabrous stem, petioles, and leaves, but fruit, sepals, fruit peduncles, and flower pedicel are covered with sparse and fine hairs, and the candidate gene for this mutation is unknown ${ }^{26}$. The csgl3 (tril) mutant is completely free from trichomes which encodes a Class IV HDZIP transcription factor; the glabrous phenotype in csgl3 is due to either SNPs or retrotransposon insertion in the coding region ${ }^{27-29}$. The $c s g l 4$ mutant has glabrous fruit skin but reduced size and number of trichomes on the stem and leaves; CsGL4 was thought to encode a C-type lectin receptor-like tyrosine-protein kinase ${ }^{2}$.

QTL for vegetative growth and development-related traits

Significant variation exists among cucumbers for size of vegetative organs such as hypocotyl length (HL), cotyledon area (CA), leaf area (LA), vine length (VL), internode length (IL), total number of nodes $(\mathrm{NN})$, lateral branch number (LBN), and whole plant (above-ground) biomass (BIO). QTL mapping studies for these traits were conducted primarily using three RIL populations from the following crosses: S94 $\times$ S06, 9110Gt $\times 9930$, and PI $183967 \times 931$ (ref. ${ }^{30-34}$ ). Details of all detected QTL for these traits and their chromosomal locations are presented in Fig. 3, and Supplementary Files 3 (Table S3) and 4 (Fig. S1).

Six moderate-effect (PVE 10\%) and one (hl6.2) largeeffect $(P V E=22.6 \%)^{32,34}$ QTL, were identified for HL in two RIL populations, but none are co-localized with sh1. QTL mapping on cotyledon/leaf length and width was conducted in two RIL populations ${ }^{32-34}$. Eight CA (cotyledon area) and five LA (leaf area) consensus QTL from these studies are listed in Supplementary File 3, of which three LA and CA QTL were co-localized suggesting possible shared mechanisms in regulation of cotyledon and leaf sizes in the two populations.

In the $9110 \mathrm{Gt} \times 9930$ RIL population, 7 QTL for plant architecture-related traits were detected including four for IL, one for NN, and two for VL. Given the role of node number and internode length on vine length, the 3 majoreffect QTL (ill.1, nn1.1, and vl1.1) are co-localized on Chr1 (Fig. 3). The number of lateral branches (LBN) varies significantly in different cucumbers. The littleleaf (ll) mutant $\mathrm{H} 19$ also has multiple lateral branches, which is likely due to the pleiotropic effect at the $l l$ locus ${ }^{16}$. In the S94 $\times$ S06 RIL population, there were 6 QTL underlying LBN variation including two major-effect QTL (lbn1.2, and lbn6.2), but none is located nearby the $l l$ locus indicating multiple mechanisms regulating branch numbers.

The observed clustering of these size- or length-related QTL for vegetative organs (Fig. 3; Supplementary File 4) on four chromosomal locations on Chr1, Chr5, and Chr6, suggest common genetic basis for these traits.

\section{Genes and QTL for reproductive development Simply inherited genes for sex determination}

A cucumber plant can bear male, female, or bisexual flowers, and their combinations result in five major sex morphs: monoecious (male and female flowers), andromonoecious (male and perfect flowers), gynoecious (female only), androecious (male only) and hermaphroditic (bisexual flowers only). In cucumber, sex determination depends primarily on the $F$ (femaleness), $m$ (andromonoecy), and a (androecy) loci, all of which are members of the aminocyclopropane-1-carboxylic acid synthase (ACS) gene families (CsACS1 for F; CsACS2 for $M$, and $C s A C S 11$ for $A$ ) catalyzing the rate-limiting step in ethylene biosynthesis ${ }^{35-37}$. The $F$ locus is consisted of two copies of $A C S 1$ (CsACS1 and CsACS1G). Additional genes or modifiers affecting sex expression also exist. For example, mutations in CsACO2 $(a-1)$ for the 1- 

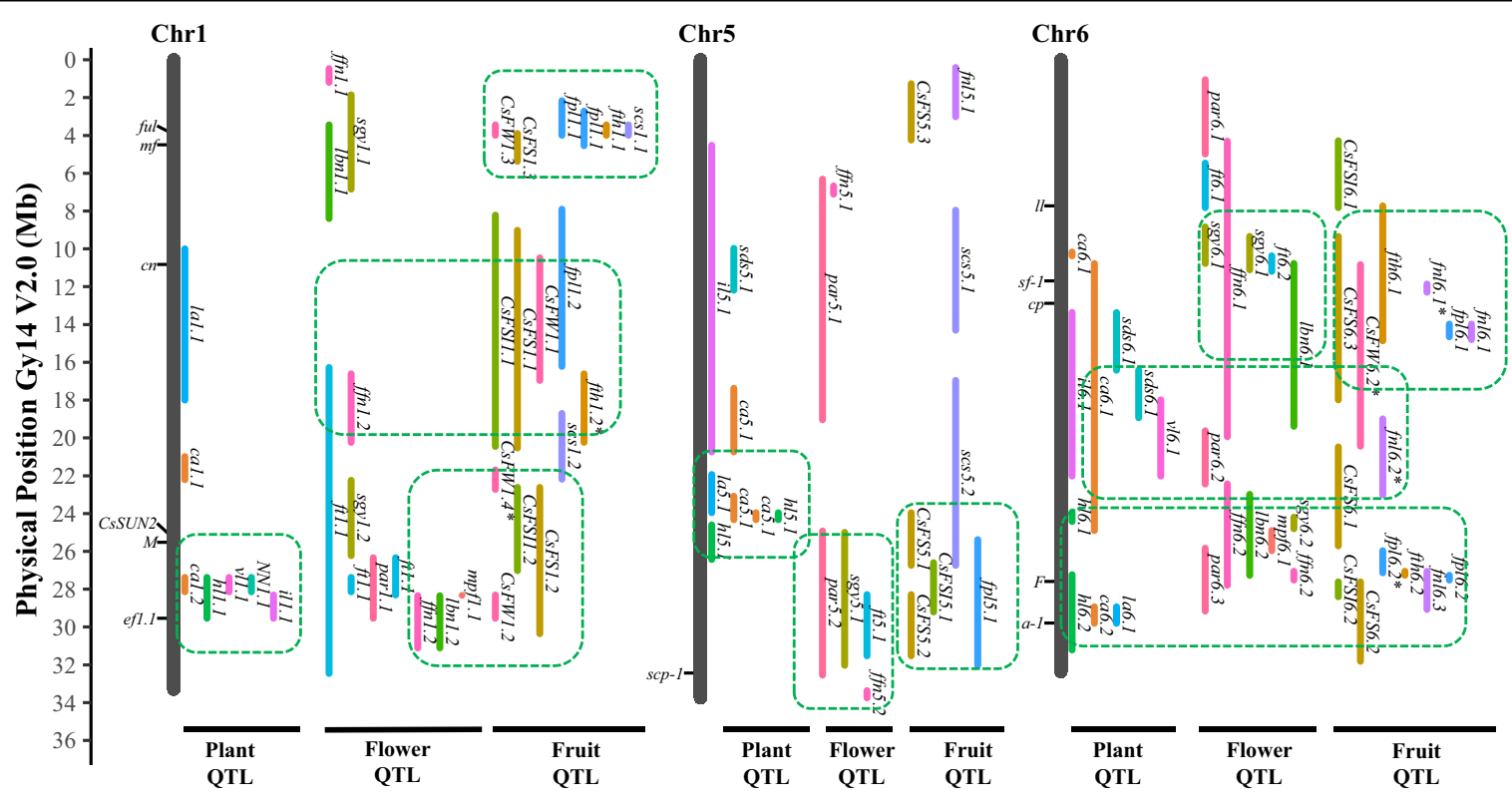

Fig. 3 Chromosomal locations of vegetable organ-, flower- and fruit set-related QTL on cucumber chromosomes 1, 5, and 6. Ruler to the left indicates locations (in Mbp) in the Gy14 V2.0 draft genome assembly (drawn to scale). Vertical black lines are chromosomes. Cloned genes and QTL are aligned to the left and right of each chromosome, respectively. Vertical bar for each QTL represents 1.5 or 2.0 LOD confidence interval on the chromosome. Dashed rectangles indicate gene/QTL hot spots or clusters. CA = cotyledon area, CsFS = consensus fruit size and shape, FFN = first flower node, $\mathrm{FT}=$ flowering time, $\mathrm{FPL}=$ fruit peduncle length, $\mathrm{FW}=$ fruit weight, $\mathrm{HL}=$ hypocotyl length, $\mathrm{IL}=$ internode length, $\mathrm{LA}=$ leaf area, $\mathrm{LBN}$ $=$ lateral branch number, MPF = multiple pistillate flowers, NN = node number, SCS = seed cavity size, SDS = seed size. SGY = sub-gynoecious, PAR $=$ Parthenocarpy, and $\mathrm{VL}=$ vine length.

aminocyclopropane-1-carboxylate oxidase result in androecy $^{38}$. A major-effect QTL, Sgy3.1, controls $F$ locusindependent high percentage of female flowers on monoecious plants ${ }^{39,40}$ (also see below). These diverse sexdetermination genes provide opportunities to fine tune sex expression for cucumber production.

\section{QTL for reproductive development-related traits Flower- and fruit set-related QTL}

Flowering time (FT) and sex expression are directly related to fruit timing and yield, respectively. The wild cucumber $(C$. s. var. hardwickii), semi-wild XIS cucumber, and some landraces from India and Pakistan require short-day length for flower induction. For example, it takes six or more months for the XIS cucumber accession WI7167 to flower under long-day conditions ${ }^{41}$, while most modern varieties will flower in 30-50 d after planting. In two studies, four QTL (ft1.1, ft5.1, ft6.1, and ft6.2) were found to control flowering time variation in populations derived from two XIS cucumber accessions (SWCC8 and WI7167) (1,42 $^{4}$ (Supplementary File 5 or Fig. S2). Two other studies used populations derived from crosses between cultivated cucumber lines with $<5 \mathrm{~d}$ FT difference. In each case, a single major-effect FT QTL (da1.1 and Ef1.1) was detected $^{32,43}$; both are very close to $f t 1.1$. It was suggested that ft6.2 in WI7167 is a major-effect QTL regulating day-length sensitive flowering while $f t 1.1$ regulates flowering time within cultivated cucumbers ${ }^{41}$.

Early fruit yield is influenced by flowering time and position of the first flower node (FFN). Nine FFN QTL were identified in two monoecious $(f f) \times$ gynoecious $(F F)$ RIL populations ${ }^{30,32,44}$. Among three major-effect FFN QTL, ffn6.2 was located near the $F$ locus as expected, while QTL $f f n 1.2$ and $f f n 3.2$ also have major effects (Fig. 3 ). These studies revealed the complicity of genetic control of the FFN trait, which is obviously the results of the interplay among factors affecting both flowering time and sex expression.

A gynoecious plant carrying the homozygous $F F$ gene has one or more female flowers on each node, which may not be ideal in some production systems with less optimal cultural practices or poor production conditions since not all female flowers will develop into marketable fruit. The term "sub-gynoecious" (SubG) type sex expression was used to describe the plant that starts with male flowers in the first 5-10 nodes and then has continuous female flowers on the main stem with an overall percentage of female flowers (PFF) of $>80 \%$ (ref. ${ }^{39}$ ). In a segregating population derived from the cross between S-2-98 (SubG) and M95 (M), 4 QTL, Sgy3.1, Sgy4.1, Sgy6.1, and Sgy6.1, were found to regulate PFF with Sgy3.1 having the strongest effect $(\mathrm{PVE}=54.6 \%)^{39}$. In another study, Win 
et al. confirmed the major-effect QTL Sgy3.1, and identified two additional QTL, Sgy1.1 and Sgy1.2, which are able to increase, and decrease PFF, respectively ${ }^{40}$ (Supplementary File 3). A gene for the GA20-oxidase was proposed to be the candidate gene for the dominantly inherited Sgy3.1 locus ${ }^{40}$. Phenotypically, an $F$ geneindependent SubG plant is similar to the one that is heterozygous at the $F$ locus $(F f)$, which usually starts with male flowers in the first few nodes (1-10) followed by continuous female flowers. When QTL mapping for PFF was conducted using populations derived from gynoecious $(F F) \times$ monoecious $(f f) \operatorname{crosses}^{44,45}$, as expected, the major-effect QTL for PFF was consistent with the $F$ locus (Fig. 3). Minor-effect PFF QTL were detected in these studies, which seem to co-localize with SubG QTL Sgy3.1 and Sgy6.1 $1^{39,40}$ (Supplementary File 5). These observations suggest the PFF is influenced by multiple genetic factors although the $F$ and Sgy3.1 loci play the major roles in gynoecious and SubG plants, respectively.

Some gynoecious cucumber lines may bear multiple pistillate flowers (MPFs) at each node. Five MPF QTL have been identified with each having similar effect (PVE $\sim 10 \%)^{46}$. Parthenocarpic fruit set (PAR) is critical for cucumber production in protected environments. Lietzow et al. and Wu et al. detected 12 PAR QTL in two sources, but only two (par2.1 and par7.1) are co-localized between the two studies ${ }^{47,48}$. The inconsistent results reflect the difficulties in accurate phenotyping for PAR, which is difficult to separate from yield.

Many of the FT- and sex-expression-related traits are correlated and may be regulated by common, hormonerelated pathways, which can be evidenced from QTL clusters for different traits on chromosomes $1,3,5,6$, and 7 (Fig. 3; Supplementary File 5).

\section{Genes and QTL for fruit-related traits \\ Genes for simply inherited fruit-related traits Fruit skin and flesh color}

Cucumber fruit exhibits a wide spectrum of skin colors that can vary from light green, yellow green, green, dark green, to creamy, white, yellow, brown, orange, or red (Fig. 1). The white skin color $(w)$ is due to a mutation in the CsAPRR2 gene, which plays an important role in fruit pigment accumulation ${ }^{49}$. Mutations in the lgp (light green peel, CsARC5) and lgf (light green fruit, CsYcf54) genes cause change of dark green fruit color to light green ${ }^{50,51}$. The orange/red mature fruit color locus $R$ is allelic to the black spine gene $B$, which encodes a R2R3 MYB transcription factor ${ }^{52,53}$.

Most cucumber fruits have white flesh. The semi-wild XIS cucumber has orange flesh (or) and accumulates highlevel $\beta$-carotene at mature fruit stage. This is due to a mutation in $C s B C H$ for $\beta$-carotene hydroxylase ${ }^{33}$. The yellow flesh $(y f)$ locus from PI 200815 was fine mapped into a $150-\mathrm{kb}$ region on Chr7 (ref. ${ }^{54}$ ). The green flesh (gf) in immature cucumber, results of accumulation of chlorophyll, is controlled by two loci ${ }^{55}$.

\section{Fruit epidermal features}

The external appearance of cucumber fruit is important for consumer acceptance or processing. Several simply inherited genes determine fruit epidermal features, some of which are tightly linked on Chr5 (Fig. 2) including Heavy/no netting $(H / h)$, Warty/smooth fruit (Tu/tu), Dull/glossy fruit skin $(\mathrm{D} / \mathrm{d})$, Ribbed/non-ribbing fruit ( $\mathrm{Fr} /$ fr), Mottled/uniform immature fruit color $(U / u)$, Large/ small spines (SS/ss), and Tough/tender fruit (Te/te). Interestingly, specific allele combinations of these genes are characteristic of different market classes. For example, the European Long, Chinese Long, and US pickling cucumbers often have $u$-H-tu-ss-te-fr-d, $u$-h-Tu-ss-te-Fr$d$, and $U-h-T u-S S-T e-f r-D$ haplotypes, respectively. This is likely the result of diversifying selection during breeding for different market classes.

The number of spines on the fruit vary widely in cucumbers of different market classes. The few spine1 $\left(f_{s} 1\right)$ mutation identified from a dense-spined Chinese Long line is due to an 812-bp deletion in the promoter region of CsGL3 (ref. ${ }^{56}$ ); but higher density spines in Chinese Long cucumber seem to require both CsGL3 and the QTL $f_{s} d 6.1$ (ref. ${ }^{57}$ ). Some cucumbers have numerous $(n s)$ but small spines (ss) with the $n s$ being a homolog for the gene encoding an auxin transporter-like protein 3 $(C s L A X 3)^{58,59}$. Fruit spines usually are hard and prickly and may cause an itching response on the skin. A tender spine (tsp) mutant does not trigger itching, which seems due to an N-terminal deletion in Tsp for a C-type lectin receptor-like tyrosine-protein kinase $^{3}$. A nonsynonymous mutation within the same gene was proposed to confer glabrous trait ( $\operatorname{csgl}$ g) with smaller and fewer trichomes ${ }^{2}$. Fruit spines often sit on a bulge structure of several layers of cells called tubercles (warts). The $\mathrm{Tu}$ (tuberculated) locus controls wart development, and Ts1 regulates tubercle size, which encodes a $\mathrm{C}_{2} \mathrm{H}_{2}$ zinc finger domain-containing transcription factor $(\mathrm{CsTu})$, and an oleosin (CsTs1), respectively; $C s T u$ can bind directly to the promoter of $C s T s 1$ to promote its expression ${ }^{60,61}$.

\section{QTL for fruit size/shape, external and internal fruit quality traits}

Fruit size and shape

Cucumber exhibits diverse fruit size (FS) and fruit shape. Fruit shape is defined using fruit shape index (FSI) which is the ratio of fruit length (FL) to fruit diameter (FD). In some cases, simply inherited genes have been found to play important roles in fruit size control. For example, the fruitful1 (CsFUL1) gene is a key player in fruit elongation in Chinese Long cucumber ${ }^{62}$. Of two short fruit mutants ( $s f-1$ and $s f-2)$ recently identified ${ }^{4,63}, s f-$ 
2 encodes a cucurbit-specific RING-type E3 ligase, which results in its enhanced self-ubiquitination and degradation, as well as increased expression CsACS2 ( $m$ locus). This may also explain the elongated fruit due to an allelic mutation of the $m$ locus $(m-1)$ on an andromonoecious plant $(m-1 m-1)$; an andromonoecious cucumber plant $(\mathrm{mm})$ usually sets round fruit ${ }^{64}$. Fruit size variation in cucumber is also influenced by fruit carpel number $(\mathrm{CN})$. $\mathrm{CN}$ variation ( 3 vs 5 ) is controlled by the $\mathrm{Cn}$ gene that is a homolog of CLAVTATA3 $(C s C L V 3)^{65}$. Cucumber fruit shape can be round, oval, oblong, long or very long. A spontaneous mutant bears mango-shaped fruit (mango fruit, $m f$ ) which is due to a SNP in the WUSCHEL-related homeobox1 (CsWOX1) gene ${ }^{66}$.

In most cases, fruit size and shape are controlled by QTL. A number of QTL mapping studies on fruit size/ shape have been conducted in cucumber. Pan et al. reviewed the genetic architecture of fruit size variation in cucumber, and identified 19 consensus fruit size (FS) and 11 fruit shape (FSI) QTL ${ }^{67}$. Among them, the consensus FS QTL FS1.2 and FS2.1 are the homologs of tomato SUN (CsSUN2) and SITRM5 (TONNEAU1 Recruiting Motif) (CsTRM4), respectively ${ }^{67-69}$. Details of these consensus FS QTL are presented in Supplementary Files 3 and 6. In addition, fruit weight (FW) is apparently correlated with fruit size, which is also an important component for fruit yield. QTL mapping have identified 19 FW QTL in three studies ${ }^{42,44,70}$ (Supplemental Files 3 and 6). Almost all FW QTL are co-localized with consensus FS QTL indicating a close correlation between them.

Two other traits often correlated with fruit length are fruit neck length (FNL) and fruit peduncle length (FPL). Fruit neck is the stem-end of the fruit with reduced fruit expansion, which usually does not have spines. Long fruit neck is an undesirable trait because it gives non-uniform external appearance and often has a bitter taste due to accumulation of cucurbitacins. FNL is strongly associated with fruit length. In the only QTL mapping study for $\mathrm{FNL}^{44}$, all five QTL were co-localized with the FS consensus QTL (Supplementary File 6). Fruit peduncle connects the stem and the fruit. There is significant variation in FPL among different cucumber market classes. Seven FPL QTL were identified in two studies ${ }^{44,71}$; all of which are co-localized with FS consensus QTL.

A fruit with small seed cavity and thick flesh is preferred for both processing and fresh market uses. Structurally, fruit seed cavity size (SCS) and fruit flesh thickness (FTH) are two traits to describe the endocarp and mesocarp of the cucumber pepo fruit, respectively. Eight and six consensus QTL have been identified for SCS and FTH, respectively ${ }^{44,72}$.

As discussed earlier, most fruit epidermal feature genes are simply inherited (Tables 1 and 2), but some show quantitative variation. For example, Tian et al. found that fruit skin wax (glaucosity) (FSW) accumulation is controlled by five QTL, with $f s w 5.1$, and $f s w 6.1$ having moderate effects $^{73}$ (Supplementary File 3). Shimomura et al. and Miao et al. examined fruit wart size (FWS) and density (FWD) and identified 3 and 2 QTL, respectively ${ }^{74,75}$. In both cases, the major-effect QTL is consistent with the $T u$ locus (Table 1). Fruit spine density on cucumber fruit may vary from very few large spines, many small spines (ss), to high-density spines or ultra-highdensity hairs (or numerous spines, ns). The $n s$ and ss single genes have been cloned or fine mapped (Tables 1 and 2). Bo et al. examined spine density in bi-parental and natural populations, and identified three QTL: $f_{s} d 6.2, f s d 6.1$, and $f_{s} d 4.1$ that control high and ultra-high spine densities, which had major-, moderate, and minor effects, respectively ${ }^{57}$. The $f s d 6.2$ locus, which is a variant of the CsGL3 gene (Table 1) regulates high spine density, but for ultrahigh spine density, both $f s d 6.1$, and $f s d 6.2$ are required.

\section{QTL for seed-related traits}

Cucumber seed did not seem to be a target of selection during long-term cultivation. Cucumber seeds are white or gray in color, but seed size does show significant variation especially between the wild and cultivated cucumbers. The wild cucumber accession PI 183967 has very small seeds. In two studied, Wang et al. and Lietzow conducted QTL analysis for seed length, width, and weight $^{76,77}$. Most QTL for the three traits are co-localized, and the seven consensus QTL for seed size (SDS) are summarized in Supplementary File 3. Seed size did not seem to have any obvious correlation with other size or length-related traits (Supplementary File 6).

\section{Genes and QTL for disease resistances and abiotic stress tolerances}

Genes for simply inherited disease resistances

Major cucumber diseases of worldwide importance include downy mildew (DM), powdery mildew (PM), angular leaf spot (ALS), target leaf spot (TLS), anthracnose (AR), Fusarium wilt (FOC), scab, and various viruses like cucumber mosaic virus (CMV), watermelon mosaic virus (WMV), zucchini yellow mosaic virus (ZYMV), and papaya ringspot virus (PRSV). The cucumber accession PI 197087 from India and its derivatives like Gy14 are resistant to DM, ALS and AR that is conferred by $d m 1$, $p s l$, and cla, respectively. It was found that the cucumber Staygreen (CsSGR) is the causal gene underlying the $d \mathrm{~m} /$ psl/cla locus (Chr5 in Fig. 2); thus, the durable resistance against the three different pathogens (bacterial, oomycete, and fungal) in Gy14 is due to a loss-of-susceptibility mutation in CsSGR, which encodes the $\mathrm{Mg}$ dechelatase that plays critical regulatory roles in the chlorophyll degradation pathway ${ }^{78,79}$. The $d m 1$-conferred DM resistance was less effective since 2004 when new DM 
pathogen strains emerged in the cucumber field in the US. Two major-effect QTL for resistance against the post2004 DM strain(s) (dm4.1 and $d m 5.2)$ were identified from PI 197088 and PI 330628 (ref. ${ }^{80,81}$ ).

Another well characterized loss-of-susceptibility $R$ gene in cucumber is the mlo locus for PM resistance ${ }^{82-84}$. Multiple allelic variants at this locus have been identified in PM resistant accessions; all result in the loss of function of CsMLO. Additional PM resistance genes near the mlo locus are also possible ${ }^{85}$ (Table 2, Fig. 2). The Chinese Long line, Jin5-508, carries a dominantly inherited PM resistance gene Pm1.1 which has been mapped in a 41.1$\mathrm{kb}$ region containing two cysteine-rich receptor-like protein kinase genes ${ }^{86}$.

Three recessively inherited TLS resistance genes, $c c a-1$, cca-2, cca-3, have bene mapped on Chr6 (Fig. 2) ${ }^{87,88}$. Among them, $c c a-3$ seems to belong to the CC-NB-ARC type $R$ gene family ${ }^{88}$ which has $\sim 73$ homologs in the cucumber genome. In addition, the closely linked $c c u$ for scab resistance and Foc for Fusarium wilt resistance were mapped to a region on Chr2 containing a cluster of several NB-LRR $R$ gene homologs ${ }^{89,90}$.

The candidate gene for the zym locus (CsVPS4) for ZYMV resistance encodes the vacuolar protein sortingassociated protein 4 (VPS4)-like protein ${ }^{91}$. Several variants of the zym locus have been identified in different ZYMV resistance sources ${ }^{92}$. Three virus resistance genes have been mapped on Chr6 including prsv for PRSV, wmv for WMV and $c m v 6.1$ for $\mathrm{CMV}^{93-95}$. Previous studies indicated tight linkage of resistances to three potyviruses (PRSV, ZYMV and WMV) in cucumber. Molecular mapping results seem to suggest that they are different loci (Fig. 2).

\section{QTL for disease resistances and abiotic stress tolerance}

QTL studies have been carried out for resistances to the following diseases: PM, DM. FOC, Gummy stem blight (GSB), Melon Yellow Spot Virus (MYSV), and the Cucurbit Yellow Stunting Disorder Virus (CYSDV). The results are summarized in Table 4, and their chromosomal locations are illustrated in Fig. 4. More details for each QTL are presented in Supplementary File 2 (Table S2).

QTL mapping for PM resistance (PMR) has been conducted from six resistance sources including PI 197088 (ref. ${ }^{81,96,97}$ ), S06 (ref. ${ }^{98}$ ), K8 and H136 (ref. ${ }^{99}$ ), WI2757 (ref. ${ }^{100}$ ), and IL52 (ref. ${ }^{85}$ ). Diverse mapping populations, phenotyping and genotyping methods were used in these studies with varying power of QTL detection. However, based on chromosomal locations of these QTL, 19 consensus PMR QTL could be inferred (Supplementary File 2). The co-localization of QTL from different resistance sources may suggest that they belong to the same locus, or are closely linked. For example, pm5.3 was detected in PI 197088, IL52, WI 2757 and K8; both pm5.1 and pm6.3 were detected in S06, K8 and PI 197088. The pm5.3 locus (syn. $p m 5.1, p m-h$ ) encodes a barley $M L O$ homolog (CsMLO1), and multiple variants at this locus are responsible for PMR in different lines ${ }^{82-84}$. The $p m /$ dm5.3 QTL has been shown to confer complete PM resistance in IL52, and the gene for a GATA transcriptional factor was proposed to be its candidate ${ }^{85}$.

QTL mapping for DM resistance (DMR) has been conducted in PI 197085, PI 197088, WI 7120 (PI 330628), WI 2757, S94, TH118FLM, IL52, and K8 (Table 4). Sixteen QTL were identified in PI 197088, and four of them are major-effect QTL contributing to DMR ( $d m 4.1$, $d m 5.1, d m 5.2$, and $d m 5.3)^{81,101,102}$. PI 330628 carries five DMR contributing QTL with $d m 4.1$ and $d m 5.2$ having the largest effect ${ }^{80}$. WI 2757 exhibits moderate resistance to post-2004 field DM strains and carries both $d m 1$ from PI 197087 and $d m 5.2$ with unknown origin ${ }^{81}$. Among the 17 consensus DMR QTL, 11 could be detected in at least two resistance sources (Table 4; Supplementary File 2). Interestingly, the two major-effect QTL, $d m 5.1$ and $d m 5.2$ were detected in five resistance sources, whereas $d m 1.1$ and $d m 6.4$ were each identified in four lines. These observations suggest that cucumbers from different origins may share some comment genetic basis for DMR although the magnitude of these QTL are affected by genetic backgrounds and environmental conditions.

QTL mapping studies for resistances to other pathogens are sporadic. Fusarium wilt is a soil-borne disease, which is more serious in cucumber production under protected environments. A major-effect QTL for Fusarium wilt resistance, Foc2.1 was identified, which is closely linked with the scab resistance $(c c u)$ locus in a region with multiple members of NB-LRR resistance gene homo$\operatorname{logs} 89,90,103$. The wild cucumber line PI 183967 is highly resistant to GSB. The adult plant and seedling GSB resistances were controlled by four and five QTL, respectively ${ }^{104,105}$, but only one minor-effect QTL (gsb6.2) is shared between the two stages. Two minor-effect GSB resistance QTL ( $g s b 4.1$, and $g s b 6.2$ ) were also detected in a C. hystrix introgression line ${ }^{106}$. For virus resistances, four QTL for the resistance to isolate MYSV-FuCu05P-2 have been identified ${ }^{107}$. A major-effect QTL for CYSDV resistance (cysdv5.1) was mapped to a region close to the $m l o$ locus for $\mathrm{PMR}^{108}$.

In cucumber breeding, it has long been observed that there is a positive correlation between resistances to different pathogens such as DMR and PMR, resistance to Fusarium wilt and scab, and resistance to different potyviruses (e.g., PRSV, and ZYMV). Indeed, several lines used in the above-mentioned QTL mapping studies possess dual resistances to PM and DM (for example, PI 197088, K8, IL52, and WI2757). The chromosomal locations of consensus resistance QTL to different pathogens are illustrated in Fig. 3. Clearly, many disease resistance QTL are co-localized, which is especially true for PM and DM. 
Table 4 Summary of disease resistance QTL identified in cucumber.

\begin{tabular}{|c|c|c|c|}
\hline Diseases $^{a}$ & Resistance Sources & QTL and effects ${ }^{b}$ & Notes \\
\hline \multirow[t]{6}{*}{ PM } & PI 197088 & $\begin{array}{l}\underline{p m 1.1}^{* *}, p m 1.3^{* *}, p m 2.1, p m 2.2, p m 3.1, p m 4.3^{*}, \underline{p m 5.1^{* *}}, p m 5.3^{* *}, p m 5.4^{* *}, \\
\underline{p m 6.1}^{* *}, \underline{p m 6.3^{* *}}, \underline{p m 7.1^{* *}}\end{array}$ & \\
\hline & S06 (Beit alpha) & $p m 1.2, p m 4.1^{* *}, p m 5.1, p m 6.3^{* *}$ & \\
\hline & WI 2757 & $p m 1.1^{* *}, p m 1.2^{*}, p m 3.2, p m 4.2^{*}, p m 5.2^{* *}, p m 5.3^{* *}$ & \\
\hline & H136 (Chinese Long) & pm1.3, pm6.2 & Detected with BSA \\
\hline & K8 (Chinese Long) & pm5.1, pm5.3**,pm6.3 & \\
\hline & IL52 (C.hystrix IL) & $p m 5.3^{* *}$ & Single gene \\
\hline \multirow[t]{8}{*}{ DM } & WI7120 (PI 330628) & $d m 2.1, d m 4.1^{* *}, d m 5.2^{* *}, d m 6.3, d m 6.4$ & \\
\hline & IL52, CCMC (Chinese Long) & $d m 1.1, d m 1.2, d m 1.3, d m 5.1^{* *}, d m 5.3^{* *}, d m 6.4$ & Three Chr1 QTL from CCMC \\
\hline & K8 & $d m 1.1^{* *}, d m 5.2^{* *}, d m 6.4$ & \\
\hline & PI 197088 & $\frac{d m 1.1}{d m 5.2^{* *}, d m 5.3^{* *}, d m 6.1, \underline{d m} 6.2, \underline{d m 6.4, d m 7.1}}$ & \\
\hline & PI 197085 & $d m 5.1^{*}, d m 5.2^{*}, d m 5.3^{*}$ & \\
\hline & S94 & $d m 1.1^{* *}, d m 5.1^{* *}$ & \\
\hline & TH118FLM & $d m 2.1^{* *}, d m 2.2^{* *}, d m 5.1^{* *}$ & $\begin{array}{l}\text { Drived from 'Malini' } \\
\text { F1 hybrid }\end{array}$ \\
\hline & WI2757 & $d m 1^{* *}, d m 5.2^{* *}$ & \\
\hline ALS & WI2757 & $p s *^{* *}$, als 1.1 , als3.1 & \\
\hline \multirow[t]{2}{*}{ FOC } & 9110Gt (European Long) & Foc2.1 $1^{* *}$ & Single gene \\
\hline & URS189 & Foc3.1, Foc5.1 & Patent \\
\hline \multirow[t]{3}{*}{ GSB } & PI 183967 (wild cucumber) & gsb1.1, gsb2.1, gsb6.1**, gsb6.2 & Mature pant resistance \\
\hline & PI 183967 & gsb3.1, gsb3.2, gsb4.1, gsb5.1**, gsb6.2 & Seedling stage resistance \\
\hline & HH1-8-1-2 (Chinese Long) & gsb4.1, gsb6.2 & Seedling stage resistance \\
\hline CYSDV & PI 250147 & cysdv5.1 & Single gene \\
\hline MYSV & Tokiwa & mysv1.1**, mysv3.1**, mysv4.1 $1^{*}$, mysv7.1 & Resistance to spotted wilt \\
\hline
\end{tabular}

${ }^{a}$ Complete references are provided in Supplementary File 1 (Table S1)

$b_{* P V E}$ (percentage of phenotypic variance explained) $=10-15 \%$; ** PVE $>15 \%$; underlined: contribute to disease susceptibility

Also, it seems there are several hot spots on chromosomes 5 and 6 where resistance loci to different pathogens are highly enriched (Fig. 3). This offers potential advantages in disease resistance breeding for cucumber. However, at the molecular level, whether these resistance genes or QTL belong to the same locus, or are closely linked await further investigation.

Cucumber is of tropical origin and is sensitive to low temperature. In temperate growing regions or production areas at a high altitude, low temperature germination (LTG) ability is a trait that may allow for early planting. In two studies ${ }^{109,110}$, four LTG QTL were identified: LTG1.1, LTG1.2, LTG2.1, and LTG4.1. The two major-effect contributing QTL, LTG1.1 and LTG1.2, are 2-Mbp apart on Chr1 (Supplementary File 3). Waterlogging is a serious environmental stress in many cucumber production regions. One strategy for cucumber plants to deal with the waterlogging stress is the production of hypocotyl-derived adventitious roots (AR). In the waterlogging resistant line Zaoer-N, three QTL contribute to increasing AR numbers under waterlogging ${ }^{111}$. The gene for an AAA-ATPase domain-containing protein has been shown to be a candidate for the major-effect QTL for adventitious root numbers, ARN6.1 $1^{112}$.

\section{Genes for MISC horticulturally important traits}

The bitter tasting cucurbitacins are tetrocylic terpenes present widely in cucurbit crops. Three bitterness related genes have been cloned including Bi (bitterfree), $B l$ (bitter leaf), and Bt (bitter fruit $)^{113}$. Bi encodes a cucurbitadienol synthase that catalyzes the cyclization of 2,3-oxidosqualene into the tetracyclic cucurbitane skeleton, the first committed step of cucurbitacin biosynthesis. Both $\mathrm{Bl}$ and $B t$ encode two basic helix-loop-helix (bHLH) 


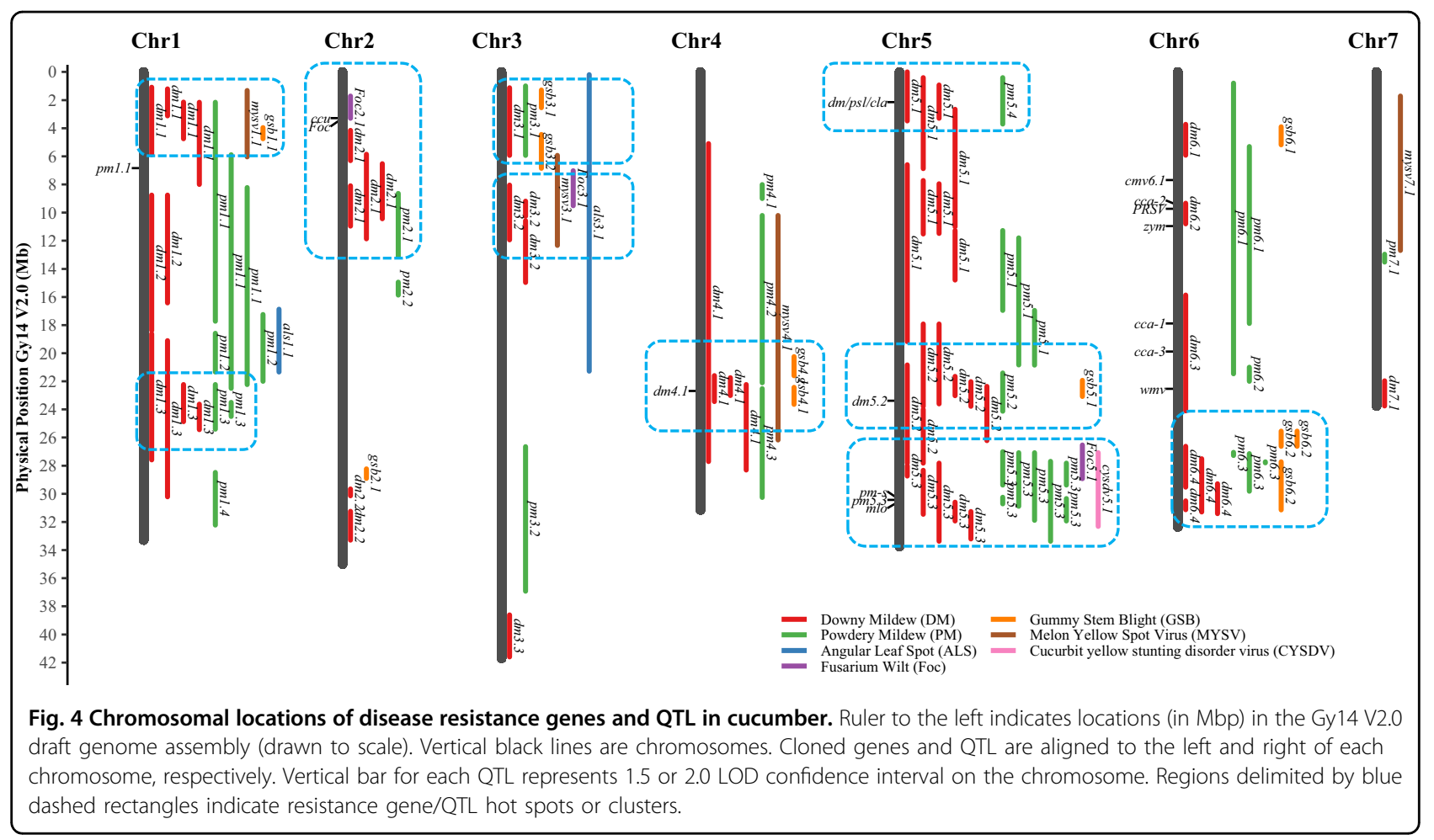

transcription factors that are expressed specifically in leaves and fruits, respectively. $B l$ binds to the E-box elements of the $B i$ promoter to activate its transcription for cucurbitacin biosynthesis in cucumber leaves; $B t$ has similar biochemical function as $B l$ but regulates cucurbitacin biosynthesis in the fruit ${ }^{113}$. Abiotic stress influences cucurbitacin biosynthesis by modulating the expression of $B l$ and/or $B t^{113}$.

Cucumber foliage or fruit are usually non-fragrant, but some varieties from Thailand have pandan-like fragrance from leaves and fruit, which is controlled by the fgr (fragrance) locus (CsBADH) encoding the betaine aldehyde dehydrogenase ${ }^{114}$.

\section{Concluding remarks}

New genomic technologies and resources for cucumber have allowed for a surge in research leading to QTL mapping and identification of candidate genes associated with a wide array of phenotypic traits. In this work we documented 81 simply inherited genes or major-effect QTL and 322 QTL for 42 quantitative traits, providing chromosome locations, allelic variants and associated polymorphisms, predicted functions where appropriate, and diagnostic markers that could be used for markerassisted selection in cucumber breeding. Despite the increased effort in cucumber, the number of cloned genes and narrowly defined QTL is still quite limited, and in most cases the proposed functions have not been verified. Looking to the future, it is anticipated that studies in cucumber will be able to draw on an increasing number of genomic tools, both to identify and verify important genes. Cucumber collections in major gene banks are rich in genetic variation that could be explored to identify novel genes or alleles. Genome-wide association analysis may play an important role to accomplish this. EMS mutagenesis is also a powerful tool to generate novel mutations and development of efficient genetic transformation and gene editing systems will allow characterization of gene functions.

It is hoped that the present work will serve as starting point for the systematic inventory of cucumber genes, quantitative trait loci, genetic stocks, and mutants, to benefit the cucurbit community in the years to come. As the information about cucumber genes continues to grow, it has also become imperative for the community to adopt a standard nomenclature to describe QTL. Standardized nomenclature, as has been adopted for numerous other species, facilitates continued progress and minimizes confusion when comparing results across publications. We hope the vocabularies for quantitative traits and the QTL naming rules we recommended here will help achieve this goal.

\section{Acknowledgements}

The authors apologize for not being able to cite all pertinent references in this review. The authors thank colleagues in the cucumber research community from both public institutions and private seed companies for their comments and suggestions in developing the list of quantitative traits, control vocabulary and QTL naming rules in cucumber. USDA is an equal opportunity provider 
and employer. This work was supported by grants from the National Institute of Food and Agriculture, U.S. Department of Agriculture, under award numbers and 2015-51181-24285 and 2017-67013-26195 (to Y.Q.W.).

\section{Author details}

'Department of Horticulture, University of Wisconsin, Madison, WI 53706, USA ${ }^{2}$ Institute of Vegetables and Flowers, Chinese Academy of Agricultural Sciences, Beijing 100081, China. ${ }^{3}$ Department of Plant Sciences, Shanghai Jiaotong University, Shanghai 200240, China. ${ }^{4}$ Horticulture College, Northwest A\&F University, Yangling 712100, China. ${ }^{5}$ Horticulture College, Nanjing Agricultural University, Nanjing 210095, China. ${ }^{6}$ Beijing Vegetable Research Center, Beijing Academy of Agricultural and Forestry Sciences, Beijing 100097 China. ${ }^{7}$ College of Horticulture Science and Engineering, Shandong Agricultural University, Tai'an 271018, China. ${ }^{8}$ College of Horticulture, China Agricultural University, Beijing 100193, China. ${ }^{9}$ College of Horticulture and Plant Protection, Yangzhou University, Yangzhou 225009, China. ${ }^{10}$ Department of Horticulture, Michigan State University, East Lansing, Ml 48824, USA. ${ }^{11}$ USDAARS Vegetable Crops Research Unit, 1575 Linden Dr., Madison, WI 53706, USA

\section{Author contributions}

Y.Q.W. conceived and supervised the study. Y.H.W. and Y.Q.W. analyzed the data and wrote the manuscript with inputs from other co-authors. K.B., X.G., J. P., Y.L., J.C., C.W., Z.R., H.R., X.C. and R.G. provided mutant, gene and Q.T.L. mapping information for genes cloned or mapped in respective labs. All authors reviewed and approved this submission.

\section{Conflict of interest}

The authors declare that they have no conflict of interest.

Supplementary Information accompanies this paper at (https://doi.org/ 10.1038/s41438-019-0226-3).

Received: 19 April 2019 Revised: 5 October 2019 Accepted: 8 November 2019

Published online: 01 January 2020

\section{References}

1. Weng, Y. \& Wehner, T. C. Cucumber Gene Catalog 2017. Cucurbit Genet. Coop. Rep. 40, 17-54 (2017).

2. $\mathrm{Xu}, \mathrm{M}$. et al. A new gene conferring the glabrous trait in cucumber identified using MutMap. Hortic. Plant J. 1, 29-34 (2015).

3. Guo, C. et al. Identification and mapping of ts (tender spines), a gene involved in soft spine development in Cucumis sativus. Theor. Appl. Genet. 131, 1-12 (2018).

4. Xin, T. et al. Genetic regulation of ethylene dosage for cucumber fruit elongation. Plant Cell 31, 1063-1076 (2019).

5. Wang, $X$. et al. An exon skipping in a SEPALLATA-Like gene is associated with perturbed floral and fruits development in cucumber. J. Integr. Plant Biol. 58, 766-771 (2016).

6. Gao, M., Hu, L., Li, Y. \& Weng, Y. The chlorophyll-deficient golden leaf mutation in cucumber is due to a single nucleotide substitution in CsCh/l for magnesium chelatase I subunit. Theor. Appl. Genet. 129, 1961-1973 (2016).

7. Miao, $\mathrm{H}$. et al. Fine mapping of virescent leaf gene $v-1$ in cucumber (Cucumis sativus L.). Int. J. Mol. Sci. 17, 1602 (2016).

8. Cao, W., Du, Y., Wang, C., Xu, L. \& Wu, T. Cscs encoding chorismate synthase is a candidate gene for leaf variegation mutation in cucumber. Breed. Sci. 581, 571-581 (2018).

9. Song, M. et al. Fine mapping of CSVYL, conferring virescent leaf through the regulation of chloroplast development in cucumber. Front. Plant Sci. 9, 432 (2018).

10. Del Valle-Echevarria, A. R., Sanseverino, W., Garcia-Mas, J. \& Havey, M. J. Pentatricopeptide repeat 336 as the candidate gene for paternal sorting of mitochondria (Psm) in cucumber. Theor. Appl. Genet. 129, 1951-1959 (2016).

11. Zhang, $C$. et al. Mutations in CSPID encoding a Ser/Thr protein kinase are responsible for round leaf shape in cucumber (Cucumis sativus L.). Theor. Appl. Genet. 131, 1379-1389 (2018).

12. Song, M. et al. A leaf shape mutant provides insight into PINOID Serine/ Threonine Kinase function in cucumber (Cucumis sativus L.). J. Integr. Plant Biol. https://doi.org/10.1111/jipb.12739 (2019).
13. Rong, F. et al. A mutation in class III homeodomain-leucine zipper (HD-ZIP III) transcription factor results in curly leaf (cul) in cucumber (Cucumis sativus L.). Theor. Appl. Genet. 132, 113-123 (2019).

14. Wang, S. et al. A rare SNP identified a TCP transcription factor essential for tendril development in cucumber. Mol. Plant 8, 1795-1808 (2015).

15. Chen, F. et al. Fine mapping identifies CsGCN5 encoding a histone acetyltransferase as putative candidate gene for tendril-less 1 mutation (td-1) in cucumber. Theor. Appl. Genet. 130, 1549-1558 (2017).

16. Yang, L. et al. LITTLELEAF ( $L L)$ encodes a WD40 repeat domain-containing protein associated with organ size variation in cucumber. Plant J. 95 834-847 (2018).

17. Van der Linden, L. Marker for compact growth in cucumber. WO/2017/ 042272 (2018)

18. $L i, Y$. et al. Fine genetic mapping of $c p$ : a recessive gene for compact (dwarf) plant architecture in cucumber, Cucumis sativus L. Theor. Appl. Genet. 123, 973-983 (2011).

19. Lin, T. et al. A truncated F-Box protein confers the dwarfism in cucumber. J. Genet. Genomics 43, 223-226 (2016).

20. Wang, $H$. et al. The cytochrome P450 gene CSCYP85A1 is a putative candidate for super compact-1 ( $\mathrm{Scp}$-1) plant architecture mutation in Cucumber (Cucumis sativus L.). Front. Plant Sci. 8, 1-13 (2017).

21. Hou, S. et al. A mutant in the CSDET2 gene leads to a systemic brassinosteriod deficiency and super compact phenotype in cucumber (Cucumis sativus L.). Theor. Appl. Genet. 130, 1693-1703 (2017).

22. Xu, L., Wang, C., Cao, W., Zhou, S. \& Wu, T. CLAVATA1-type receptor-like kinase CSCLAVATA1 is a putative candidate gene for dwarf mutation in cucumber. Mol. Genet. Genomics 293, 1393-1405 (2018).

23. Bo, K. et al. SHORT HYPOCOTYL1 encodes a SMARCA3-Like chromatin remodeling factor regulating elongation. Plant Physiol. 172, 1273-1292 (2016).

24. Li, Q. et al. The identification of Cucumis sativus Glabrous 1 (CSGL1) required for the formation of trichomes uncovers a novel function for the homeodomain-leucine zipper I gene. J. Exp. Bot. 66, 2515-2526 (2015).

25. Zhao, J. et al. Micro-trichome as a class I homeodomain-leucine zipper gene regulates multicellular trichome development in Cucumis sativus. J. Integr. Plant Biol. 57, 925-935 (2015).

26. Yang, $\mathrm{S}$. et al. Genetic analysis and mapping of $\mathrm{g} / \mathrm{-2}$ gene in cucumber (Cucumis sativus L.). Acta Hortic. Sin. 38, 1685-1692 (2011).

27. Pan, Y., Bo, K., Cheng, Z. \& Weng, Y. The loss-of-function GLABROUS 3 mutation in cucumber is due to LTR-retrotransposon insertion in a class IV HD-ZIP transcription factor gene CsGL3 that is epistatic over CSGL1. BMC Plant Biol. 15, 1-15 (2015).

28. Cui, J. et al. A new glabrous gene (csg/3) Identified in trichome development in cucumber (Cucumis sativus L.). PLoS ONE 11, e0148422 (2016).

29. Wang, Y. et al. Identification and mapping of Tril, a homeodomain-leucine zipper gene involved in multicellular trichome initiation in Cucumis sativus. Theor. Appl. Genet. 129, 305-316 (2016).

30. Jiang, S., Yuan, X., Pan, J., He, H. \& Cai, R. Quantitative trait locus analysis of lateral branch-related traits in cucumber Cucumis sativus L.) using recombinant inbred lines. Sci. China Ser. C Life Sci. 51, 833-841 (2008).

31. Miao, $\mathrm{H}$. et al. Detection of quantitative trait loci for plant height in different environments using an RIL population in cucumber. Sci. Agric. Sin. 45, 4552-4560 (2012).

32. Miao, H. et al. Mapping QTLs for seedling-associated traits in cucumber. Acta Hortic. Sin. 39, 879-887 (2012).

33. Qi, J. et al. A genomic variation map provides insights into the genetic basis of cucumber domestication and diversity. Nat. Genet. 45, 1510-1515 (2013).

34. Wang, M. et al. QTL mapping of seedling traits in cucumber using recombinant inbred lines. Plant Breed. 135, 124-129 (2016).

35. Li, Z. et al. Molecular isolation of the $M$ gene suggests that a conservedresidue conversion induces the formation of bisexual flowers in cucumber plants. Genetics 182, 1381-1385 (2009).

36. Boualem, A. et al. A cucurbit androecy gene reveals how unisexual flowers develop and dioecy emerges. Science 350, 688-691 (2015).

37. Zhang, Z. et al. Genome-wide mapping of structural variations reveals a copy number variant that determines reproductive morphology in cucumber. Plant Cell 27, 1595-1604 (2015).

38. Chen, $\mathrm{H}$. et al. An ACC oxidase gene essential for cucumber carpel development. Mol. Plant 9, 1315-1327 (2016).

39. $\mathrm{Bu}, \mathrm{F}$. et al. A major quantitative trait locus conferring subgynoecy in cucumber. Theor. Appl. Genet. 129, 97-104 (2016). 
40. Win, K. T. et al. Identification of quantitative trait loci governing subgynoecy in cucumber. Theor. Appl. Genet. 132, 1505-1521 (2019).

41. Pan, Y. et al. QTL mapping of domestication and diversifying selection related traits in round-fruited semi-wild Xishuangbanna cucumber (Cucumis sativus L. var. xishuangbannanesis). Theor. Appl. Genet. 130, 1531-1548 (2017).

42. Bo, K, Ma, Z., Chen, J. \& Weng, Y. Molecular mapping reveals structural rearrangements and quantitative trait loci underlying traits with local adaptation in semi-wild Xishuangbanna cucumber (Cucumis sativus L. var. xishuangbannanesis Qi et Yuan). Theor. Appl. Genet. 128, 25-39 (2015).

43. Lu, H. et al. QTL-seq identifies an early flowering QTL located near Flowering Locus T in cucumber. Theor. Appl. Genet. 127, 1491-1499 (2014).

44. Yuan, X. et al. Genetic mapping and QTL analysis of fruit and flower related traits in cucumber (Cucumis sativus L.) using recombinant inbred lines. Euphytica 164, 473-491 (2008).

45. Fazio, G., Staub, J. E. \& Stevens, M. R. Genetic mapping and QTL analysis of horticultural traits in cucumber (Cucumis sativus L.) using recombinant inbred lines. Theor. Appl. Genet. 107, 864-874 (2003).

46. Miao, H. et al. Mapping QTLs for multiple pistillate flowers in cucumber. Acta Agron. Sin. 37, 1449-1455 (2010).

47. Lietzow, C. D., Zhu, H., Pandey, S., Havey, M. J. \& Weng, Y. QTL mapping of parthenocarpic fruit set in North American processing cucumber. Theor. Appl. Genet. 129, 2387-2401 (2016)

48. Wu, Z. et al. Identification of a stable major-effect QTL (Parth 2.1) controlling parthenocarpy in cucumber and associated candidate gene analysis via whole genome re-sequencing. BMC Plant Biol. 16, 1-14 (2016).

49. Liu, H. et al. Map-based cloning, identification and characterization of the $w$ gene controlling white immature fruit color in cucumber (Cucumis sativus $\mathrm{L}$ ). Theor. Appl. Genet. 129, 1247-1256 (2016).

50. Zhou, Q. et al. An accumulation and replication of chloroplasts 5 gene mutation confers light green peel in cucumber. J. Integr. Plant Biol. 57, 936-942 (2015).

51. Lun, Y. et al. A CsYcf54 variant conferring light green coloration in cucumber. Euphytica 208, 509-517 (2016).

52. Li, Y., Wen, C. \& Weng, Y. Fine mapping of the pleiotropic locus B for black spine and orange mature fruit color in cucumber identifies a $50 \mathrm{~kb}$ region containing a R2R3-MYB transcription factor. Theor. Appl. Genet. 126, 2187-2196 (2013).

53. Liu, M. et al. CSMYB60 is a key regulator of flavonols and proanthocyanidans that determine the colour of fruit spines in cucumber. J. Exp. Bot. 70, 69-84 (2019)

54. $\mathrm{Lu}, \mathrm{H}$. et al. Molecular mapping and candidate gene analysis for yellow fruit flesh in cucumber. Mol. Breed. 35, 64 (2015).

55. Bo, K. et al. QTL mapping and genome-wide association study reveal two novel loci associated with green flesh color in cucumber. BMC Plant Biol. 19, 1-13 (2019).

56. Zhang, H. et al. A fragment substitution in the promoter of CSHDZIV11/CSGL3 is responsible for fruit spine density in cucumber (Cucumis sativus L.). Theor. Appl. Genet. 129, 1289-1301 (2016).

57. Bo, K. et al. Novel loci fsd6.1 and Csg/3 regulate ultra-high fruit spine density in cucumber. Theor. Appl. Genet. 132, 27-40 (2019).

58. Zhang, S. et al. Molecular mapping and candidate gene analysis for numerous spines on the fruit of cucumber. J. Hered. 107, 471-477 (2016).

59. Xie, Q. et al. Combined fine mapping, genetic diversity, and transcriptome profiling reveals that the auxin transporter gene ns plays an important role in cucumber fruit spine development. Theor. Appl. Genet. 131, 1239-1252 (2018).

60. Yang, $X$. et al. Tuberculate fruit gene $T u$ encodes a $\mathrm{C}_{2} \mathrm{H}_{2}$ zinc finger protein that is required for the warty fruit phenotype in cucumber (Cucumis sativus L.). Plant J. 78, 1034-1046 (2014).

61. Yang, S. et al. A CSTU-TS1 regulatory module promotes fruit tubercule formation in cucumber. Plant Biotechnol. J. 17, 289-301 (2019).

62. Zhao, J. et al. A functional allele of CSFUL1 regulates fruit length through repressing CSSUP and inhibiting auxin transport in cucumber. Plant Cell 31, 1289-1307 (2019).

63. Wang, L. et al. Transcriptomic analysis of short-fruit 1 (sfl) reveals new insights into the variation of fruit-related traits in Cucumis sativus. Sci. Rep. 7, 2950 (2017).

64. Tan, J. et al. A novel allele of monoecious ( $m$ ) locus is responsible for elongated fruit shape and perfect flowers in cucumber (Cucumis sativus L.). Theor. Appl. Genet. 128, 2483-2493 (2015).
65. Li, S. et al. Integrated analysis in bi-parental and natural populations reveals CSCLAVATA3 (CSCLV3) underlying carpel number variations in cucumber. Theor. Appl. Genet. 129, 1007-1022 (2016).

66. Niu, H. et al. The WUSCHEL-related homeobox1 gene of cucumber regulates reproductive organ development. J. Exp. Bot. 69, 5373-5387 (2018).

67. Pan, Y. et al. Genetic architecture of fruit size variation in cucurbits: a comparative perspective. Theor. Appl. Genet. https://doi.org/10.1007/s00122-01903481-3 (2019).

68. Pan, Y. et al. Round fruit shape in W17239 cucumber is controlled by two interacting quantitative trait loci with one putatively encoding a tomato SUN homolog. Theor. Appl. Genet. 130, 573-586 (2017).

69. Wu, S. et al. A common genetic mechanism underlies morphological diversity in fruits and other plant organs. Nat. Commun. 9, 1-12 (2018).

70. Wei, Q. et al. An SNP-based saturated genetic map and QTL analysis of fruitrelated traits in cucumber using specific-length amplified fragment (SLAF) sequencing. BMC Genomics 15, 10 (2014).

71. Song, Z. et al. Genetic analysis and QTL mapping of fruit peduncle length in cucumber (Cucumis sativus L.). PLOS ONE 11, e0167845 (2016).

72. Xu, X. et al. QTL mapping of cucumber fruit flesh thickness by SLAF-seq. Sci. Rep. 5, 15829 (2015).

73. Tian, G. et al. Genetic analysis and QTL mapping of wax powder on the surface of cucumber fruit. Sci. Agric. Sin. 48, 3666-3675 (2015).

74. Shimomura, K. et al. Quantitative trait locus analysis of cucumber fruit morphological traits based on image analysis. Euphytica 213, 1-13 (2017).

75. Miao, H. et al. Mapping QTLs for fruit-associated traits in Cucumis sativus L Sci. Agric. Sin. 44, 5031-5040 (2011).

76. Wang, M. et al. Inheritance analysis and QTL mapping of cucumber seed size. Acta Agron. Sin. 41, 63-72 (2014).

77. Lietzow, C. D. Characterization and QTL Mapping of Parthenocarpic Fruit Set in Processing Cucumber (Cucumis sativus L). (ProQuest LLC, Ann Arbor, Ml, 2015).

78. Pan, J. et al. STAYGREEN (CSSGR) is a candidate for the anthracnose (Colletotrichum orbiculare) resistance locus cla in Gy14 cucumber. Theor. Appl. Genet. 131, 1577-1587 (2018).

79. Wang, Y. et al. STAYGREEN, STAY HEALTHY: a loss-of-susceptibility mutation in the STAYGREEN gene provides durable, broad-spectrum disease resistances for over 50 years of US cucumber production. New Phytol. 221, 415-430 (2019).

80. Wang, Y. et al. QTL mapping for downy mildew resistance in cucumber inbred line WI7120 (PI 330628). Theor. Appl. Genet. 129, 1493-1505 (2016).

81. Wang, Y. et al. QTL mapping of downy and powdery mildew resistances in PI 197088 cucumber with genotyping-by-sequencing in RIL population. Theor. Appl. Genet. 131, 597-611 (2018).

82. Nie, J. et al. Identification and fine mapping of pm5.1: a recessive gene for powdery mildew resistance in cucumber (Cucumis sativus L.). Mol. Breed. 35, 7 (2015).

83. Nie, J. et al. Loss-of-Function mutations in CSMLO1 confer durable powdery mildew resistance in cucumber (Cucumis sativus L.). Front. Plant Sci. 6, 1-14 (2015).

84. Berg, J. A. et al. A transposable element insertion in the susceptibility gene CsaMLO8 results in hypocotyl resistance to powdery mildew in cucumber. BMC Plant Biol. 15, 243 (2015).

85. Zhang, $\mathrm{K}$. et al. Complete resistance to powdery mildew and partial resistance to downy mildew in a Cucumis hystrix introgression line of cucumber were controlled by a co-localized locus. Theor. Appl. Genet. 131, 2229-2243 (2018).

86. $\mathrm{Xu}, \mathrm{X}$. et al. Fine mapping of a dominantly inherited powdery mildew resistance major-effect QTL, Pm1.1, in cucumber identifies a $41.1 \mathrm{~kb}$ region containing two tandemly arrayed cysteine-rich receptor-like protein kinase genes. Theor. Appl. Genet. 129, 507-516 (2016).

87. $\mathrm{Fu}, \mathrm{H}$. et al. EST-SSR markers and artificial inoculation identification of leaf spot resistance in cucumber germplasm. China Hortic. Abstr. 2, 1-3 (2012).

88. Wen, $\mathrm{C}$. et al. Fine genetic mapping of target leaf spot resistance gene cca-3 in cucumber, Cucumis sativus L. Theor. Appl. Genet. 128, 2495-2506 (2015).

89. Zhang, $S$, et al. A major quantitative trait locus conferring resistance to fusarium wilt was detected in cucumber by using recombinant inbred lines. Mol. Breed. 34, 1805-1815 (2014).

90. Kang, $\mathrm{H}$. et al. Fine genetic mapping localizes cucumber scab resistance gene Ccu into an R gene cluster. Theor. Appl. Genet. 122, 795-803 (2011). 
91. Amano, M. et al. High-resolution mapping of zym, a recessive gene for Zucchini yellow mosaic virus resistance in cucumber. Theor. Appl. Genet. 126, 2983-2993 (2013).

92. Ramírez-Madera, A. O. \& Havey, M. J. Different haplotypes encode the same protein for independent sources of Zucchini Yellow Mosaic Virus resistance in cucumber. HortScience 52, 1040-1042 (2017)

93. Tian, G. et al. Genetic analysis and gene mapping of papaya ring spot virus resistance in cucumber. Mol. Breed. 35, 110 (2015).

94. Tian, G. et al. Genetic analysis and fine mapping of Watermelon mosaic virus resistance gene in cucumber. Mol. Breed. 36, 1-11 (2016).

95. Shi, L. et al. Inheritance and QTL mapping of cucumber mosaic virus resistance in cucumber (Cucumis Sativus L.). PLOS ONE 13, e0200571 (2018).

96. Fukino, N., Yoshioka, Y., Sugiyama, M., Sakata, Y. \& Matsumoto, S. Identification and validation of powdery mildew (Podosphaera xanthii)-resistant loci in recombinant inbred lines of cucumber (Cucumis sativus L.). Mol. Breed. 32, 267-277 (2013).

97. Sakata, Y. et al. QTL analysis of powdery mildew resistance in cucumber (Cucumis sativus L.). Theor. Appl. Genet. 112, 243-250 (2006).

98. Liu, L. et al. Quantitative trait loci for resistance to powdery mildew in cucumber under seedling spray inoculation and leaf disc infection. J. Phytopathol. 156, 691-697 (2008).

99. Zhang, S. et al. QTL mapping of resistance genes to powdery mildew in cucumber (Cucumis sativus L.). Sci. Agric. Sin. 44, 3584-3593 (2011).

100. He, X. et al. QTL mapping of powdery mildew resistance in WI2757 cucumber (Cucumis sativus L). Theor. Appl. Genet. 126, 2149-2161 (2013).

101. Yoshioka, Y., Sakata, Y., Sugiyama, M. \& Fukino, N. Identification of quantitative trait loci for downy mildew resistance in cucumber (Cucumis sativus L.). Euphytica 198, 265-276 (2014).

102. Li, L., He, H., Zou, Z. \& Li, Y. QTL analysis for downy mildew resistance in cucumber inbred line PI 197088. Plant Dis. 102, 1240-1245 (2018).
103. Zhang, S. et al. Genetic mapping of the scab resistance gene in cucumber. J. Am. Soc. Hortic. Sci. 135, 53-58 (2010).

104. Liu, S. et al. Genetic analysis and QTL mapping of resistance to gummy stem blight in Cucumis sativus seedling stage. Plant Dis. 101, 1145-1152 (2017).

105. Zhang, S. et al. Inheritance and QTL mapping of resistance to gummy stem blight in cucumber stem. Mol. Breed. 37, 1-8 (2017).

106. Lou, L. et al. Genetic mapping of gummy stem blight (Didymella bryoniae) resistance genes in Cucumis sativus-hystrix introgression lines. Euphytica 192, 359-369 (2013).

107. Sugiyama, M. et al. Mapping of quantitative trait loci for Melon yellow spot virus resistance in cucumber (Cucumis sativus L.). Euphytica 205, 615-625 (2015).

108. Faber, N. M., Torres, L. M. \& Sanchez, L. O. Method of breeding CYSDVresistant cucumber plants. European patent \#EP09775344A (2008).

109. Song, Z. et al. Identification of QTLs controlling low-temperature tolerance during the germination stage in cucumber (Cucumis sativus L.). Plant Breed. 137, 629-637 (2018).

110. Yagcioglu, M. et al. QTL mapping of low temperature germination ability in cucumber. Euphytica 215, 84 (2019).

111. Xu, X., Ji, J., Xu, Q., Qi, X. \& Chen, X. Inheritance and quantitative trail loci mapping of adventitious root numbers in cucumber seedlings under waterlogging conditions. Mol. Genet. Genomics 292, 353-364 (2017).

112. $\mathrm{Xu}, \mathrm{X}$. et al. The major-effect quantitative trait locus CSARN6.1 encodes an AAA ATPase domain-containing protein that is associated with waterlogging stress tolerance by promoting adventitious root formation. Plant J. 93, 917-930 (2018).

113. Shang, $Y$. et al. Biosynthesis, regulation, and domestication of bitterness in cucumber. Science 346, 1084-1088 (2014).

114. Yundaeng, C., Somta, P., Tangphatsornruang, S., Chankaew, S. \& Srinives, P. A single base substitution in $B A D H / A M A D H$ is responsible for fragrance in cucumber (Cucumis sativus L.), and development of SNAP markers for the fragrance. Theor. Appl. Genet. 128, 1881-1892 (2015). 